Article

\title{
Provision of Frequency Stability of an Islanded Microgrid Using a Novel Virtual Inertia Control and a Fractional Order Cascade Controller
}

\author{
Soroush Oshnoei ${ }^{1}$, Mohammadreza Aghamohammadi ${ }^{1}$, Siavash Oshnoei ${ }^{2}$, Arman Oshnoei ${ }^{1,3}$ \\ and Behnam Mohammadi-Ivatloo ${ }^{3,4, * \text { (D) }}$
}

1 Department of Electrical Engineering, Shahid Abbaspour School of Engineering, Shahid Beheshti University, Tehran 19839-69411, Iran; s_oshnoei@sbu.ac.ir (S.O.); m_aghamohammadi@sbu.ac.ir (M.A.); arman_oshnoei@yahoo.com (A.O.)

2 Department of Electrical Engineering, Urmia Branch, Islamic Azad University, Urmia 57169-63896, Iran; siavash_oshnoei68@yahoo.com

3 Department of Energy Technology, Aalborg University, 9220 Aalborg, Denmark

4 Faculty of Electrical and Computer Engineering, University of Tabriz, Tabriz 51666-16471, Iran

* Correspondence: bmohammadi@tabrizu.ac.ir

check for

updates

Citation: Oshnoei, S.;

Aghamohammadi, M.; Oshnoei, S.;

Oshnoei, A.; Mohammadi-Ivatloo, B.

Provision of Frequency Stability of an

Islanded Microgrid Using a Novel

Virtual Inertia Control and a

Fractional Order Cascade Controller.

Energies 2021, 14, 4152. https://

doi.org/10.3390/en14144152

Academic Editor: Mohamed Benbouzid

Received: 30 May 2021

Accepted: 5 July 2021

Published: 9 July 2021

Publisher's Note: MDPI stays neutral with regard to jurisdictional claims in published maps and institutional affiliations.

Copyright: (c) 2021 by the authors. Licensee MDPI, Basel, Switzerland. This article is an open access article distributed under the terms and conditions of the Creative Commons Attribution (CC BY) license (https:/ / creativecommons.org/licenses/by/ $4.0 /)$.

\begin{abstract}
Nowadays, the renewable energy sources in microgrids (MGs) have high participation to supply the consumer's demand. In such MGs, the problems such as the system frequency stability, inertia, and damping reduction are threatened. To overcome this challenge, employing the virtual inertia control (VIC) concept in the MG structure could be considered as a viable solution to improve the system frequency response. Hence, this work proposes a novel modeling for VIC in an islanded MG that provides simultaneous emulation of the primary frequency control, virtual inertia, and damping. To show the efficiency of the proposed technique, a comparison is made between the dynamic performance of the proposed VIC and conventional VIC under different scenarios. The results indicate that the proposed VIC presents superior frequency performance in comparison with conventional VIC. In addition to VIC modeling, a new cascade controller based on three-degrees of freedom and fractional-order controllers (FOCs) is proposed as an MG secondary controller. The effectiveness of the proposed controller is compared to tilt-integral-derivative and FO proportional-integral-derivative controllers. The Squirrel search algorithm is utilized to obtain the optimal coefficients of the controllers. The results demonstrate that the proposed controller improves the MG frequency performance over other controllers. Eventually, the sensitivity analysis is performed to investigate the robustness of the proposed controller in the face of the variations of the parameters.
\end{abstract}

Keywords: islanded microgrid; frequency control; virtual inertia control; secondary control

\section{Introduction}

Nowadays, the focus on renewable energy sources (RESs) is increasing as a suitable alternative to replace the traditional power plants because of the shortage of fossil fuel resources, economic costs, and environmental problems. Microgrid (MG) is the integration of a number of RESs / distributed generators (DGs), such as wind turbine generators (WTG), diesel engine generators (DEG), photovoltaic (PV), fuel cell (FC), microturbine (MT), and energy storage systems (ESSs), such as battery ESS (BESS) and flywheel ESS (FESS), along with the loads. The weather conditions have a direct impact on the generation power of the RESs. Due to the intermittent nature of the RESs, it is necessary to utilize the ESSs in the MGs [1,2]. In [3], the authors proposed an energy planning model to analyze the different future energy scenarios in the islanded systems. To validate the proposed model, the authors considered the indices of total primary energy supply and $\mathrm{CO}_{2}$ emission. The authors in [4] showed that the natural gas systems coupled with electricity can improve 
the RESs integration with power grids. In [5], the authors investigated the modeling and optimization of grid-integrated plans of PVs according to electricity tariffs for residential load. To improve the frequency performance of the power systems integrated with BESS and WT, the authors in [6] presented control strategies based on VI. In [7], the authors applied a power-to-gas (P2G) method to an optimization planning model for natural gas systems coupled with electricity. Additionally, the authors analyzed the effects of a P2G method-based planning model on grid structure of the considered system.

MGs have two operation modes, islanded and grid-connected mode. In grid-connected mode, the frequency and voltage of the MGs are determined via the main grid [8-11]. In islanded mode, some MG resources are responsible for balancing power generation and demand. Hence, MG control in an islanded mode is more complex in comparison with the grid-connected mode [10-12]. Compared to traditional synchronous generators, power exchange between inverter-interfaced RESs and MG will reduce the total system inertia and primary frequency regulation. Therefore, high penetration of RESs can lead to loss of primary frequency regulation and inertia response [11]. Such conditions may cause rapid and severe variations in MG frequency, even for small perturbations. Hence, it seems essential to employ suitable techniques in the islanded MG for improving the inertia and frequency regulation.

To improve the MG inertia, a technique of virtual inertia (VI) emulation has been presented to provide an extra VI into the MG. The derivative technique is one of the efficient approaches for the emulation of the VI [11-13]. Recently, the application of VI in islanded MG has been investigated in [12-19] to improve MG frequency stability. In [12,14], the authors investigated the virtual inertia control (VIC) based on H_ $\infty$ in ESS to support the MG frequency response. Lack of VIC in MGs causes grid instability and cascading failures in the frequency events. In [13], the authors propose the derivative technique-based VI in the ultra-capacitor to stabilize the MG frequency. The authors of [11] proposed an extended virtual synchronous generator (VSG) to enhance the system inertia and the frequency stability of the system. A survey about inertia response and frequency regulation strategies for RESs has been presented in [20]. To improve the system frequency regulation, the authors in [15] used the synchronous compensators and BESS. The dynamic performance of the synthetic inertia control based on fuzzy logic has been studied in [16] to mimic the frequency oscillations in power grids. The application of the robust VIC-based coefficient diagram method controller is investigated in [17] to improve the frequency response of the islanded MG. The VIC for a renewable power generator is investigated in [18] to provide the variable VI and improve the transient stability in the interconnected power systems. Novel modeling for VIC based on the derivative technique has been investigated in [19] to emulate the virtual damping (VD) and VI simultaneously, and stabilize the frequency regulation of an islanded MG.

As reviewed, there is no research on the appropriate modeling for VIC that improves the MG frequency stability by providing features of the PFC, damping, and inertia simultaneously. This paper addresses the application of the VIC for BESS in a low-inertia MG by providing the properties PFC, VD, and VI, simultaneously.

In addition to the proper modeling for VIC, improving the secondary frequency control (SFC) is another aim of this paper. The secondary control adjusts the frequency deviations of the MG to zero after each load variation and generation supply. Hence, the utilization of appropriate control strategies in the SFC loop is necessary to improve the MG frequency regulation. In this regard, investigations related to the importance of the MG secondary controller have been conducted. The integer order controllers (IOCs), such as integral (I) [12,14,17,19-21], proportional-integral (PI) [11,16,22], proportionalintegral-derivative (PID) [13], model predictive control (MPC) [23-25], and fractional order controllers (FOCs) $[26,27]$, have been utilized in the literature to improve the performance of the MG secondary frequency control.

The three-degrees of freedom (3DOF) controllers in comparison with 1DOF and 2DOF controllers have high efficiency in terms of set-point following and adjustment in the 
presence of disturbance inputs [28,29]. The authors in [28] presented a PID controller based on 3DOF as a secondary controller to solve the automatic generation control (AGC) problem in interconnected power systems.

Nowadays, the complexities of the MGs are increasing, and it is clear that the classical controllers cannot present appropriate performance against sudden changes in load and generation. As a solution to this challenge, the cascade controllers are introduced [30]. To improve the system performance, the cascade controllers employ two feedback control loops in their structure. The advantages of cascade controllers compared to controllers with one feedback control loop are presented in [30]. Additionally, the authors in [30] propose the application of the cascade tilt-integral-tilt-derivative controller to improve the frequency regulation of the power grid. In [31], the performance of a cascade fuzzy PID-FOI controller is evaluated to improve the AGC of the power grids. Authors in [32] present an FO-based cascade controller as a secondary controller of an interconnected power system. In [29], a cascade controller based on 2DOF, named a 2DOF-PI\&FOPD controller, is employed as a secondary controller of an interconnected power grid.

According to the aforementioned discussions, employing a cascade controller based on FOCs and 3DOF has not been addressed yet. Accordingly, this work proposes a novel cascade controller based on 3DOF-tilt-integral-derivative (3DOF-TID) and fractional-order proportional-integral-derivative (FOPID) controllers as a secondary controller. The squirrel search algorithm (SSA) is utilized to obtain the optimal coefficients of the considered controller.

The contributions of this study are summarized as:

- A novel modeling for VIC is presented that provides simultaneous emulation of the PFC, VI, and VD to improve the MG frequency response.

- The dynamic efficiency of the proposed VIC is compared with conventional VIC under different scenarios.

- A novel cascade controller based on FOCs and 3DOF, named the 3DOF-TID\&FOPID controller, is proposed as a secondary frequency controller.

- The SSA is employed to obtain the optimal values of the proposed controller.

- The sensitivity analysis is performed to evaluate the performance of the proposed controller versus the changes of the system parameters.

The remainder of this article is as follows: In Section 2, the MG dynamic modeling based on frequency regulation is explained. Moreover, Section 2 presents the proposed VIC modeling for BESS. In Section 3, the design process of the proposed cascade 3DOF TID\&FOPID controller as an MG secondary controller is investigated. Section 4 explains the optimization problem formulation to obtain the suitable coefficients of the proposed controller. The simulation results are discussed in Section 5. Eventually, the conclusion of the paper is presented in Section 6.

\section{System Configuration}

Figure 1 demonstrates the configuration of the studied islanded MG for this work. According to Figure 1, the investigated MG includes several kinds of generation resources, such as WTG, PV panel, FC, conventional DEG, BESS, and FESS, along with the load. As illustrated in Figure 1, the DGs/RESs are connected to the MG via power electronic-based interfaces. WTG and PV do not take part in the frequency control. Hence, the generation power of these resources will change the MG operating point. This condition significantly affects the MG frequency regulation. Therefore, ESSs are installed in MG. Here, BESS is equipped with the VIC. The communication lines of the green (dashed line) and the red (dotted line) in Figure 1 are utilized for exchanging information and control instructions, such as inertia response, primary control, and secondary control. The power line of black (solid line) is utilized for exchanging the required power. 


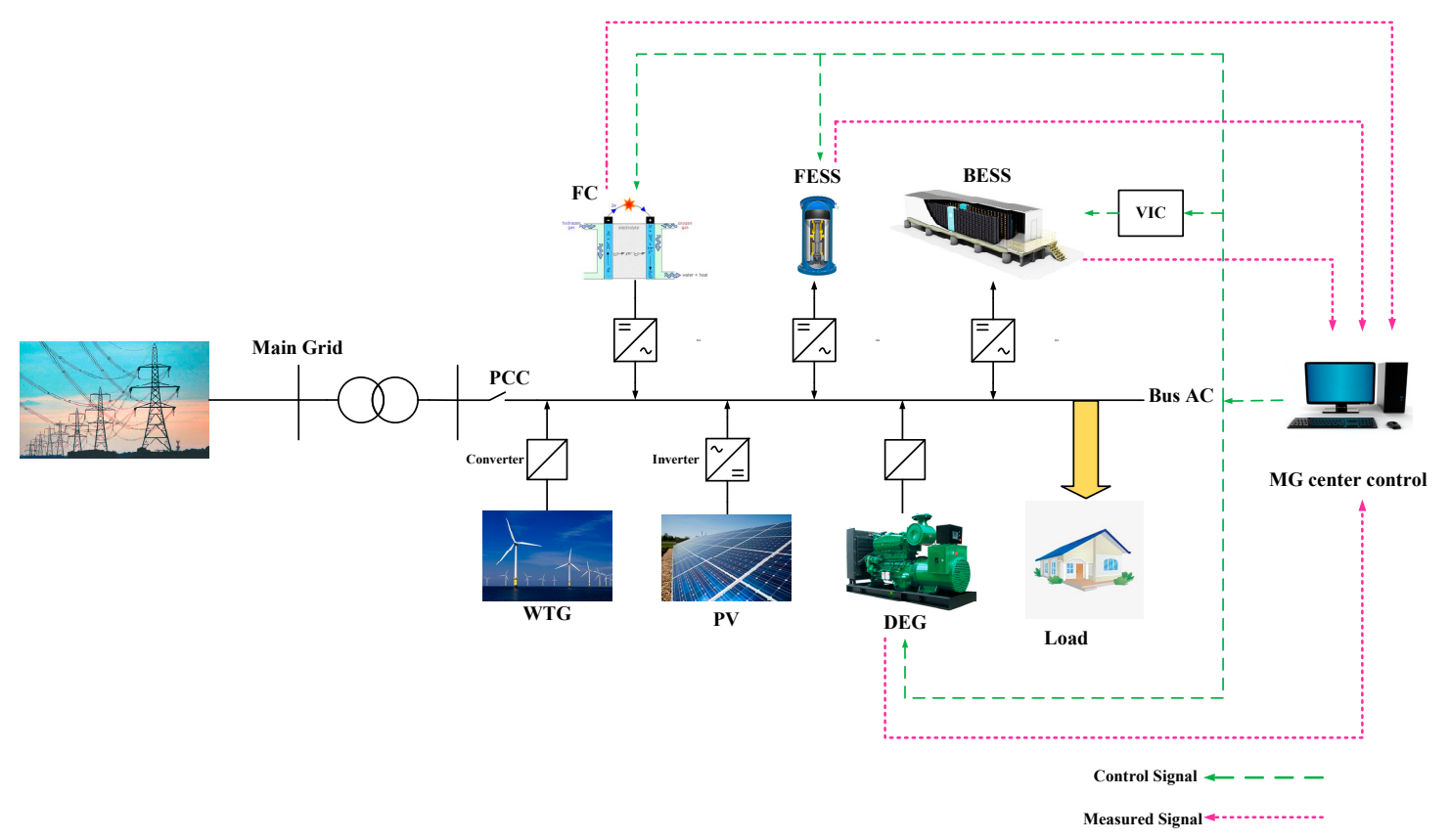

Figure 1. Simplified model of the islanded MG.

\subsection{Microgrid Modeling}

The frequency stability depends on the power balance between generation supply and demand. When the imbalance occurs, the MG frequency deviates from the nominal value. Hence, the MG control center is responsible for restoring the rebalance between generation power and demand. In order to analyze the frequency stability issue, the dynamic model of the islanded MG is shown in Figure 2. The VIC is constructed for BESS. The WTG and PV do not take part in the frequency regulation problem. Therefore, the powers of WTG, $\mathrm{PV}$, and load are considered as the perturbations of the investigated MG. However, the sources of the DEG and FC contribute to control the MG frequency. Hence, it is necessary to employ a proper control strategy in MG. In this work, a novel controller based on the combination of the 3DOF, cascade, and FO controllers, named as the 3DOF-TID\&FOPID cascade controller, is proposed as a secondary controller.

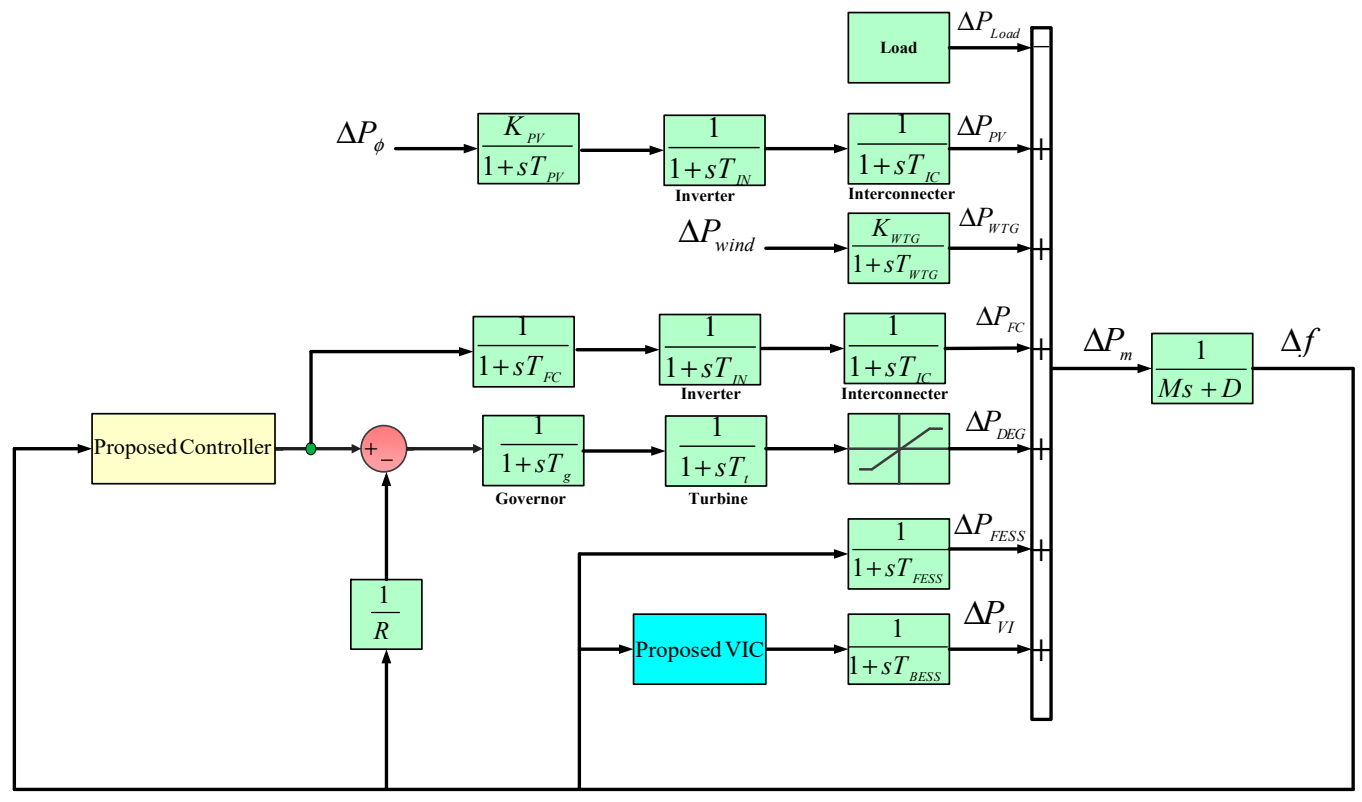

Figure 2. Transfer function model of the islanded MG. 
The relation between MG frequency deviation and inertia constant is denoted as follows:

$$
\Delta f=\frac{1}{M s+D}\left[\Delta P_{m}-\Delta P_{L}\right]
$$

where

$$
\Delta P_{m}=\Delta P_{D E G}+\Delta P_{F C}+\Delta P_{W T G}+\Delta P_{P V}+\Delta P_{B E S S}+\Delta P_{F E S S}
$$

$\Delta P_{m}$ and $\Delta P_{L}$ are the generation and load power changes of the MG, respectively. $M$ and $D$ denote the inertia and damping constants of the $M G$, respectively. According to Figure 2, $T_{P V}, T_{W T G}, T_{F C}, T_{F E S S}$, and $T_{B E S S}$ show the time constants of the PV, WTG, FC, FESS, and BESS, respectively. $K_{P V}$ and $K_{W T G}$ express the gains of the PV and WTG, respectively. $T_{g}$ and $T_{t}$ are the governor and turbine time constants of DEG, respectively. $R$ is the coefficient of the DEG governor speed regulation. Additionally, $T_{I N}$ and $T_{I C}$ indicate the time constants of the inverter and interconnector, respectively. The values of the investigated MG parameters are provided in Appendix A.

\subsection{Modeling of the Proposed Virtual Inertia Control for BESS}

VIC is an efficient solution to emulate the characteristics of the SG inertia and improve the stability of the low-inertia MG. The main idea to emulate the VIC is the derivative technique, in which its structure for BESS is depicted in Figure 3a. The derivative technique evaluates the rate of change of frequency (ROCOF) to adjust the active power of BESS to the system set-point value during perturbations. Due to the hypersensitivity of the derivative control to noise, a low-pass filter is employed in the control system. To limit the maximum and minimum energy capacity of the BESS, the limiter block is considered for BESS. The BESS power based on conventional VIC is represented as:

$$
\Delta P_{V I, B E S S}^{c o n}=\frac{K_{V I}}{1+s T_{B E S S}}\left(\frac{d(\Delta f)}{d t}\right)
$$

where $K_{V I}$ denotes the gain of the VI and $\Delta f$ is the frequency deviation of the MG.

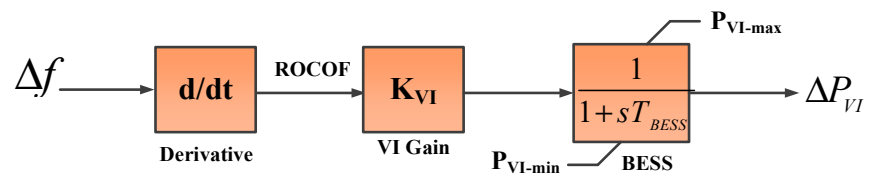

(a)

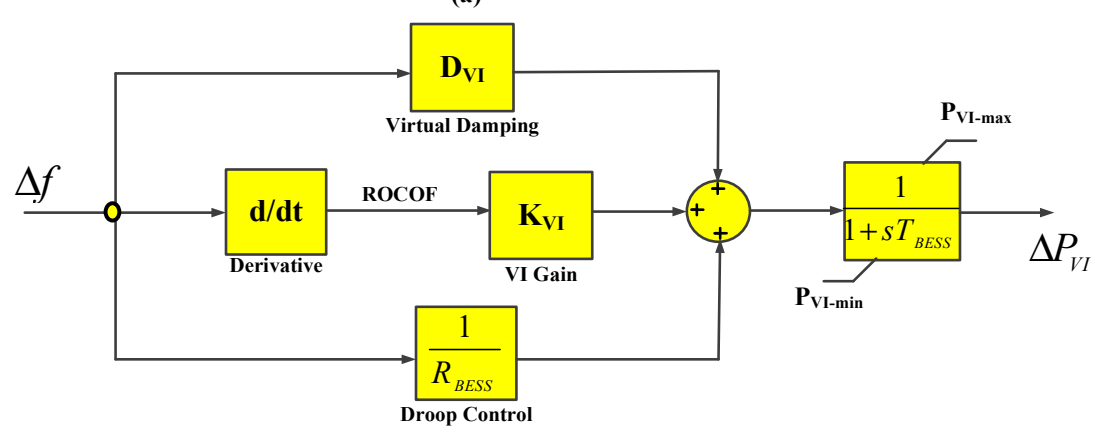

(b)

Figure 3. The dynamic structures of the VIC. (a) Conventional VIC. (b) Proposed VIC.

This study proposes novel modeling for VIC to improve the MG frequency response. The block diagram of the proposed VIC is depicted in Figure 3b. According to Figure 3b, the proposed VIC emulates the features of the VI, VD, and PFC, simultaneously. The proposed VIC provides the VI and VD in positions of low inertia and damping when the penetration of the RESs increases. The VI part assigns the ROCOF to modify the added active power to the MG set-point value during contingencies. The VD part in the proposed VIC is developed to stabilize the time based on MG frequency change. Moreover, the 
proposed VIC simulates the PFC through droop control. Accordingly, the proposed VIC technique is capable of participating in improving the MG frequency regulation. This technique can play the role of a supporter for the conventional SGs. Considering the characteristics of the proposed VIC, it can be said that the proposed VIC can improve the MG frequency performance more than the conventional VIC during contingencies. The BESS power based on the proposed VIC is represented as:

$$
\Delta P_{V I, B E S S}^{\text {nov }}=\left[K_{V I, B E S S}\left(\frac{d(\Delta f)}{d t}\right)+D_{V I} \cdot \Delta f+\frac{1}{R_{B E S S}} \cdot \Delta f\right] \frac{1}{1+s T_{B E S S}}
$$

where $R_{B E S S}$ and $D_{V I}$ show the droop and VD of the proposed VIC, respectively. The values of the $R_{B E S S}$ and $D_{V I}$ are equal to 0.001 and 3.5, respectively.

\section{The Proposed Cascade Controller Based on 3DOF and FOCs in the MG Structure}

As mentioned, it is necessary to design a suitable control strategy in the MG secondary control loop to dampen the frequency fluctuations and improve the frequency regulation of the islanded MG. Hence, a novel FO cascade controller based on 3DOF, named as the 3DOF-TID\&FOPID cascade controller, for the MG secondary controller is proposed. This section is divided into two subsections, the design of the cascade controller based on fractional-order and the design of the 3DOF-based TID controller.

\subsection{Design of the Fractional-Order Cascade Controller}

The combination concept of the cascade controller and FOCs is known as FOCC. FOCs expand IOC to a FO operator $\left(a D_{t}^{\alpha}\right)$. It can be defined mathematically as:

$$
{ }_{a} D_{t}^{\alpha}=\left\{\begin{array}{cc}
\frac{d^{\alpha}}{d d^{\alpha},} & \Re(\alpha)>0 \\
1, & \Re(\alpha)=0 \\
\int_{a}^{t}(d \tau)^{a}, & \Re(\alpha)<0
\end{array}\right.
$$

where $a$ and $t$ show the operating limits, and $\alpha$ denotes the order of integration. There are manners such as Riemann-Liouville ( $R-L)$, Grünwald-Letnikov (G-L), Riesz, and Caputo in the literature to definite the fractional calculus process, of which the $R-L$ definition is more common than the others $[27,32,33]$. The $R$ - $L$ definition can be found in $[27,32,33]$.

FOPID and TID controllers are two main types of FOCs. Generally, the transfer functions of the FOPID and TID controllers are presented by:

$$
\begin{aligned}
& \text { FOPID }=K_{P}+\frac{K_{I}}{s^{\lambda}}+K_{D} s^{\mu} \\
& T I D=K_{T} s^{-\left(\frac{1}{n}\right)}+\frac{K_{I}}{s}+K_{D} s
\end{aligned}
$$

where $K_{P}, K_{I}, K_{T}$, and $K_{D}$ indicate the adjustable proportional, integral, tilt, and derivative coefficients, respectively. $\lambda$ and $\mu \mu$ show the integral and derivative fractional-order operators of the FOPID controller in the range of $(0,1)$, respectively. $n$ shows the FO operator of the tilt term of the TID controller, which is determined in the range of $(2,3)$ from the beginning of the optimization. In this study, $n=3$ is considered. The FOPID and TID controllers in comparison with the PID controller have two more degrees and one more degree of freedom, respectively. Hence, these controllers can improve overshoot, settling time, and noise rejection in comparison with the IOCs. In this study, for FOPID and TID applications, the fifth-order Oustaloup's rational recursive approximation is considered in the frequency range of $\omega \in \in(0.01,100)$.

The concept of cascade control is originated from the control of two sequential processes. This controller is mostly utilized for rejecting the perturbation in a comparatively faster method before transmitting it to other parts of the plant. In comparison with the single-loop control, employing the cascade control can enhance the efficiency of the con- 
trol system [30-32]. The block diagram of the cascade control is illustrated in Figure 4. According to Figure 4, in the structure of the cascade control, there are two control loops of $C_{1}(s)$ and $C_{2}(s)$, which show the transfer functions of the master and slave controllers, respectively. $G_{1}(s)$ and $G_{2}(s)$ are the transfer functions of the outer and inner loop plants, respectively. $Y(s)$ is the final output of the system. The outer loop controls the final output quality to achieve a reference signal $R(s)[30,31]$. The equation of the outer loop is expressed by:

$$
Y(s)=G_{1}(s) U_{1}(s)+D_{1}(s)
$$

where $D_{1}(s)$ and $U_{1}(s)$ are load disturbance and outer process input, respectively. $U_{1}(s)$ is the input of the outer loop, $U_{1}(s)=y_{2}(s)$.

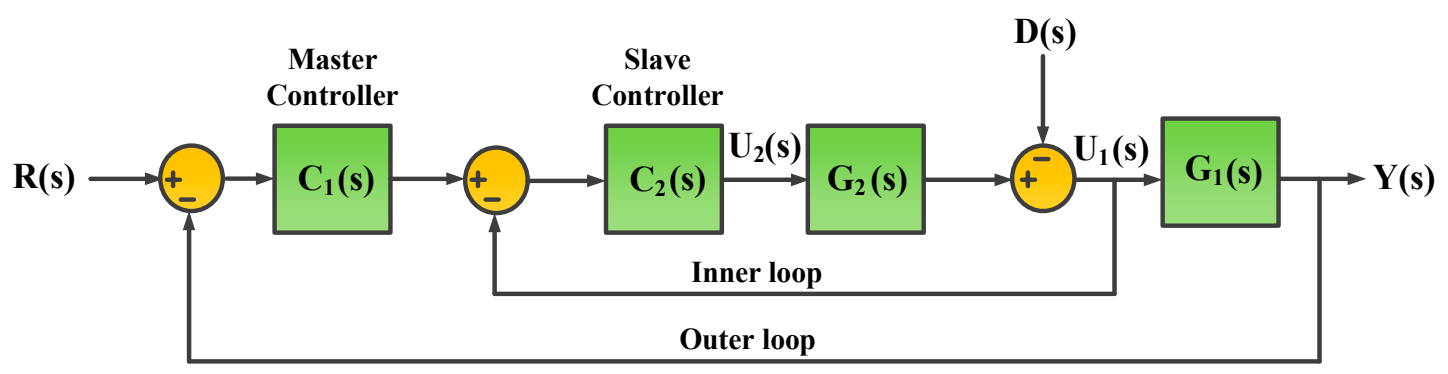

Figure 4. Block diagram of the cascade controller.

The output of the inner loop provides the outer loop in sequence and reduces the effect of any perturbation. The equation of the inner loop is represented by (9):

$$
y_{2}(s)=G_{2}(s) U_{2}(s)
$$

where $U_{2}(s)$ is the input of the inner loop.

\subsection{Design of the 3DOF-Based TID Controller}

The description of the DOF in a control system is the regulation of the number of closed-loop transfer functions, independently. The advantages of 2DOF-based control systems over $1 \mathrm{DOF}$ are reported in [28]. In this paper, the 3DOF-based control system for TID is considered. The different components for designing the 3DOF controller are as follows: (i) closed-loop stability, (ii) appointing the closed-loop response, and (iii) perturbation elimination [28]. The structure of the 3DOF controller is depicted in Figure 5. According to Figure 5, $R(s)$ is the input reference signal, $K(s)$ shows the feedback from the output of the considered system, $P(s)$ is the model of the plant, $J(s)$ is the 1DOF controller, $D(s)$ indicates the load disturbance, and $R_{C}(s)$ and $F F_{C}(s)$ are the controllers of the input reference and feed-forward, respectively. The block diagram of the 3DOF-TID controller is illustrated in Figure 6. The closed-loop equation for the 3DOF-TID controller is represented by (10):

$$
K(s)=\left[\frac{J(s) P(s)}{1+J(s) P(s)} R_{c}(s)\right] R(s)+\left[\frac{P(s)-J(s) P(s) F F_{c}(s)}{1+J(s) P(s)}\right] D(s)
$$

where $J(s)$ provides closed-loop stability, and $J(s)$ and $R_{C}(s)$ stabilize the quality of the static and dynamic of the output $Y(s) / R(s)$, respectively. Satisfying (11) leads to the removal of the $D(s)$ via the feed-forward controller $F F_{C}(s)$ :

$$
P(s)-J(s) P(s) F F_{\mathcal{c}}(s)=0
$$




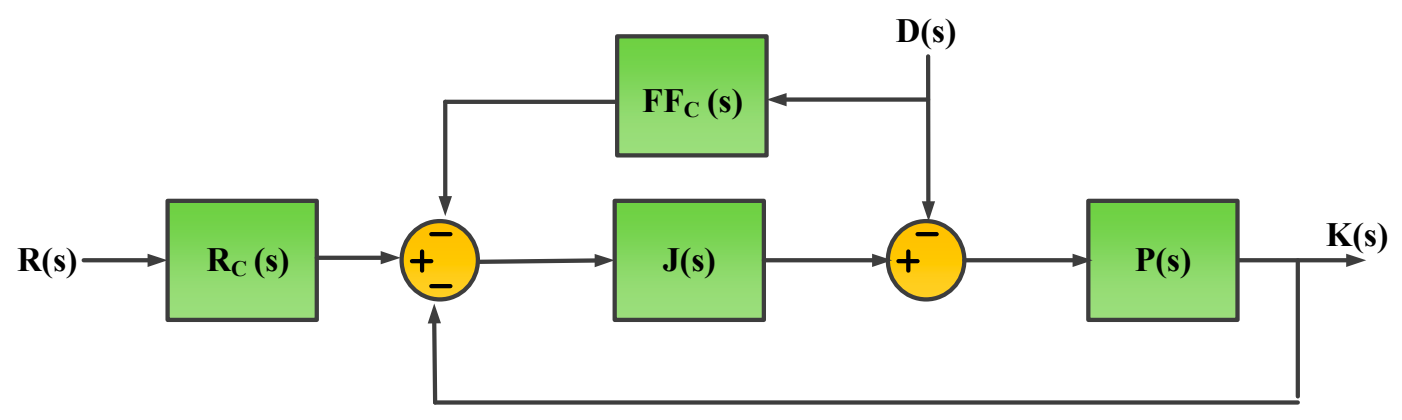

Figure 5. Three-degrees of freedom controller structure.

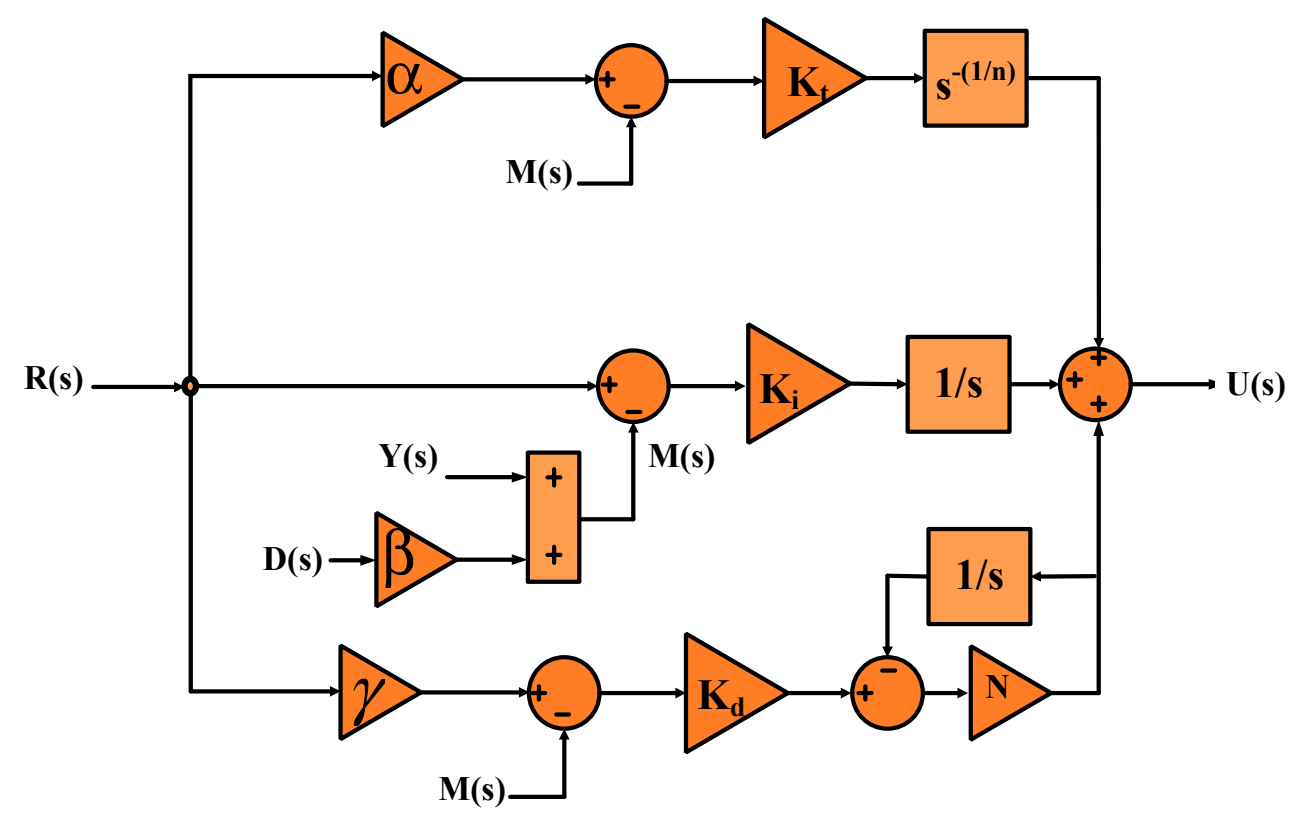

Figure 6. Block diagram of the 3DOF-TID controller.

Hence, it is necessary to update the $F F_{C}(s)$ parameter due to the changing $J(s)$ parameter.

In this study, the 3DOF-TID and FOPID controllers are combined to form a cascade controller as the MG secondary controller, where 3DOF-TID and FOPID controllers are $C_{1}(s)$ and $C_{2}(s)$, respectively. $C_{1}(s)$ and $C_{2}(s)$ are represented by (12) and (13) respectively, as:

$$
\begin{gathered}
C_{1}(s)=[\alpha \cdot R(s)-(Y(s)+\beta \cdot D(s))] K_{T} \cdot s^{-\left(\frac{1}{n}\right)}+[R(s)-(Y(s)+\beta \cdot D(s))] K_{I} \cdot \frac{1}{s}+ \\
{[\gamma R(s)-(Y(s)+\beta \cdot D(s))] \cdot K_{D} \cdot s \cdot \frac{N}{s+N}} \\
C_{2}(s)=K_{P}+\frac{K_{I}}{s^{\lambda}}+K_{D} s^{\mu}
\end{gathered}
$$

Thus, the closed loop transfer function which evaluates the overall performance of the cascaded system is provided by (14):

$$
\begin{aligned}
Y(s)= & {\left[\frac{G_{1}(s) G_{2}(s) C_{1}(s) C_{2}(s)}{1+G_{2}(s) C_{2}(s)+G_{1}(s) G_{2}(s) C_{1}(s) C_{2}(s)}\right] R(s)+} \\
& {\left[\frac{G_{1}(s)}{1+G_{2}(s) C_{2}(s)+G_{1}(s) G_{2}(s) C_{1}(s) C_{2}(s)}\right] D_{1}(s) }
\end{aligned}
$$

To complete the proposed controller design, the adjustable, gains, set-points of the 3DOF, orders of the tilt, integral, and derivative are simultaneously optimized via SSA. Figure 7 demonstrates the structure of the proposed 3DOF-TID\&FOPID cascade controller. 




Figure 7. Block diagram of the 3DOF-TID\&FOPID cascade controller.

\section{Optimization Method to Obtain the Optimal Coefficients of the Proposed Controller}

To evaluate the efficiency of the proposed 3DOF-TID\&FOPID controller, considering a suitable objective function is necessary. In this study, the objective function of the integral of time multiplied squared error (ITSE) is considered as a constrained optimization problem, as follows [26,27]:

Objective Function:

$$
\text { ITSE }=\int_{0}^{T_{\text {sim }}} t[\text { error }]^{2} d t
$$

where in this paper,

$$
\text { Min } \quad \text { ITSE }=\int_{0}^{T_{\text {sim }}} t[\Delta f]^{2} d t
$$

Decision Variables:

$$
K_{P}, K_{I}, K_{D}, K_{T}, \alpha, \beta, \gamma, \lambda, \mu
$$

Subject to:

$$
\begin{gathered}
K_{I_{\text {min }}} \leq K_{I} \leq K_{I_{\text {max }}}, \quad K_{P_{\text {min }}} \leq K_{P} \leq K_{P_{\max }} \\
K_{D_{\text {min }}} \leq K_{D} \leq K_{D_{\text {max }}}, \quad K_{T_{\text {min }}} \leq K_{T} \leq K_{T_{\max }} \\
\alpha_{\text {min }} \leq \alpha \leq \alpha_{\text {max }}, \beta_{\text {min }} \leq \beta \leq \beta_{\text {max }} \\
\gamma_{\text {min }} \leq \gamma \leq \beta_{\text {max }}, 0 \leq \lambda, \mu \leq 1
\end{gathered}
$$

where $T_{\text {sim }}$ and $\Delta f$ show the simulation time and MG frequency deviation, respectively. It should be mentioned that the SSA is utilized to achieve the suitable coefficients of the controller subject to the constraints.

\section{Squirrel Search Algorithm (SSA)}

SSA is a swarm intelligence technique based on the developed population recently introduced by Jain [34]. This optimization technique is originated from the dynamic scavenging behavior of southern flying squirrels and an effective moving pattern known as gliding. Gliding is an efficient mechanism utilized by small mammals for food collection in a large region. During warm weather, the squirrels eat acorn nuts. Then, they search for hickory nuts and store them for winter. During cold weather, the activities of the squirrels decrease, and they preserve daily energy needs with the storage of hickory nuts. The framework of the SSA technique is as follows [34,35].

Define the input parameters of the SSA: The following parameters are regulated at the beginning of the SSA process: Iter $r_{\max }$ (maximum number of iteration), NP (the population 
size), $n$ (the number of decision variables), $P_{d p}$ (the predator attendance probability), $s f$ (the scaling factor), $G_{C}$ (the gliding constant), and $F S_{U}$ and $F S_{L}$ (the upper and lower bounds for each decision variable).

Allocate the initial location for the flying squirrels randomly: The initial location of the flying squirrels are randomly allocated as:

$$
F S_{i, j}=F S_{L}+U(0,1) \times\left(F S_{U}-F S_{L}\right) i=1,2, \ldots, N P, \quad j=1,2, \ldots, n
$$

The random number $U(0,1)$ is set within the range $[0,1] . F S_{i, j}$ shows the $j$ th of the $i$ th flying squirrel.

Evaluate the fitness of location of flying squirrels: The fitness value for the location of each flying squirrel is computed by putting the decision variables' value into a fitness function, and the fitness value related to the location of each flying squirrel is stored from the minimum value to the maximum value in the following array:

$$
f=\left[\begin{array}{c}
f_{1}\left(F S_{1,1}, F S_{1,2}, \ldots, F S_{1, n}\right) \\
\vdots \\
f_{N P}\left(F S_{N P, 1}, F S_{N P, 2}, \ldots, F S_{N P, n}\right)
\end{array}\right]
$$

The fitness value corresponding to the location of each flying squirrel shows the quality of food sources defined by it, i.e., hickory nut tree $F S_{h t}$ (location of the best food source), acorn nuts tree $F S_{a t}$ (location of the normal food source), and normal tree $F S_{n t}$.

Create new locations: According to the above-mentioned facts, three cases may happen subsequent to the dynamic scavenging of flying squirrels.

Case 1: Flying squirrels at $F S_{a t}$ may move towards $F S_{h t}$. Therefore, the new locations of flying squirrels can be calculated as:

$$
F S_{a t}^{t+1}=\left\{\begin{array}{cc}
F S_{a t}^{t}+d_{g} \times G_{c} \times\left(F S_{h t}^{t}-F S_{a t}^{t}\right), & R_{1} \geq P_{d p} \\
\text { Random location } & \text { otherwise }
\end{array}\right.
$$

The random number, $R_{1}$, is set within the range $[0,1]$ and $t$ indicates the current iteration.

Case 2: Some flying squirrels at $F S_{n t}$ may move towards $F S_{a t}$ to provide their energy requirements. Hence, the new locations of flying squirrels can be generated as:

$$
F S_{n t}^{t+1}=\left\{\begin{array}{cc}
F S_{n t}^{t}+d_{g} \times G_{c} \times\left(F S_{a t}^{t}-F S_{n t}^{t}\right), & R_{2} \geq P_{d p} \\
\text { Random location } & \text { otherwise }
\end{array}\right.
$$

Similar to $R_{1}, R_{2}$ is set within the range [0,1].

Case 3: Some flying squirrels at $F S_{n t}$ may move towards $F S_{h t}$ to reserve the hickory nuts, which are useful when food sources are in shortage.

$$
F S_{n t}^{t+1}=\left\{\begin{array}{cc}
F S_{n t}^{t}+d_{g} \times G_{c} \times\left(F S_{h t}^{t}-F S_{n t}^{t}\right), & R_{3} \geq P_{d p} \\
\text { Random location } & \text { otherwise }
\end{array}\right.
$$

where $R_{3}$ is a random number within [0,1]. In all cases, the values of $P_{d p}$ and $G_{c}$ are considered to be 0.1 and 1.9 , respectively. $d_{g}$ shows random gliding distance, which can be obtained as [35]:

$$
d_{g}=\frac{h_{g}}{\tan (\varphi) \times s f}
$$

The values of $h_{g}$ and $s f$ are 8 and 18, respectively. $\tan (\varphi)$ shows the gliding angle, obtained as follows:

$$
\tan (\varphi)=\frac{D}{L}
$$


where $D$ and $L$ represent the drag and lift force, obtained as:

$$
\begin{aligned}
D & =\frac{1}{2 \rho V^{2} S C_{D}} \\
L & =\frac{1}{2 \rho V^{2} S C_{L}}
\end{aligned}
$$

Evaluate the seasonal supervising situation: Seasonal variations significantly influence the foraging behavior of the flying squirrels [34,35]. Thus, it is necessary to consider a seasonal supervising condition in the method in order to save the results from being trapped in local solutions.

The computation of the seasonal constant $\left(S_{C}\right)$ and corresponding minimum value are as follows:

$$
\begin{gathered}
S_{c}^{t}=\sqrt{\sum_{k=1}^{d}\left(F S_{a t, k}^{t}-F S_{h t, k}\right)^{2}}, t=1,2,3 \\
S_{c_{\text {min }}}=\frac{10 e^{-6}}{(365)^{t /\left(\text { ter }_{\text {max }} / 2.5\right)}}
\end{gathered}
$$

In case $S_{c}^{t}<S_{c_{\min }}$, the winter season is ended, and the flying squirrels which are not able to find the food during the winter season will relocate their situations for searching the food source:

$$
F S_{n t}^{\text {new }}=F S_{L}+\operatorname{Levy}(n) \times\left(F S_{U}-F S_{L}\right)
$$

where Lévy distribution is an efficient mathematical instrument to improve the global exploration of search space:

$$
\operatorname{Levy}(x)=0.01 \times \frac{r_{a} \times \sigma}{\left|r_{b}\right|^{1 / \beta}}
$$

where $r_{a}$ and $r_{b}$ show the two normally distributed random numbers which are set in the range of $[0,1], \beta$ is a constant (here, $\beta=1.5$ ), and $\sigma$ is calculated by (32):

$$
\sigma=\left(\frac{\Gamma(1+\beta) \times \sin \left(\frac{\pi \beta}{2}\right)}{\Gamma\left(\frac{1+\beta}{2}\right) \times \beta \times 2^{\left(\frac{\beta-1}{2}\right)}}\right)^{1 / \beta}
$$

where $\Gamma(\mathrm{x})=(\mathrm{x}-1)$ !.

Stop criterion: The algorithm finishes if $t=$ iter $_{\max }$. Figure 8 shows the flowchart of SSA. The optimal coefficients of the controllers are presented in Table 1. In [34,35], the efficiency of SSA is compared with grey wolf optimization (GWO), genetic algorithm (GA), firefly algorithm (FA), artificial bee colony (ABC) algorithm, bat algorithm (BA), particle swarm optimization (PSO), differential evolution (DE), and evolutionary programming (EP). The results indicated that SSA has the capability to bestow with better-quality solutions than other optimization algorithms. 


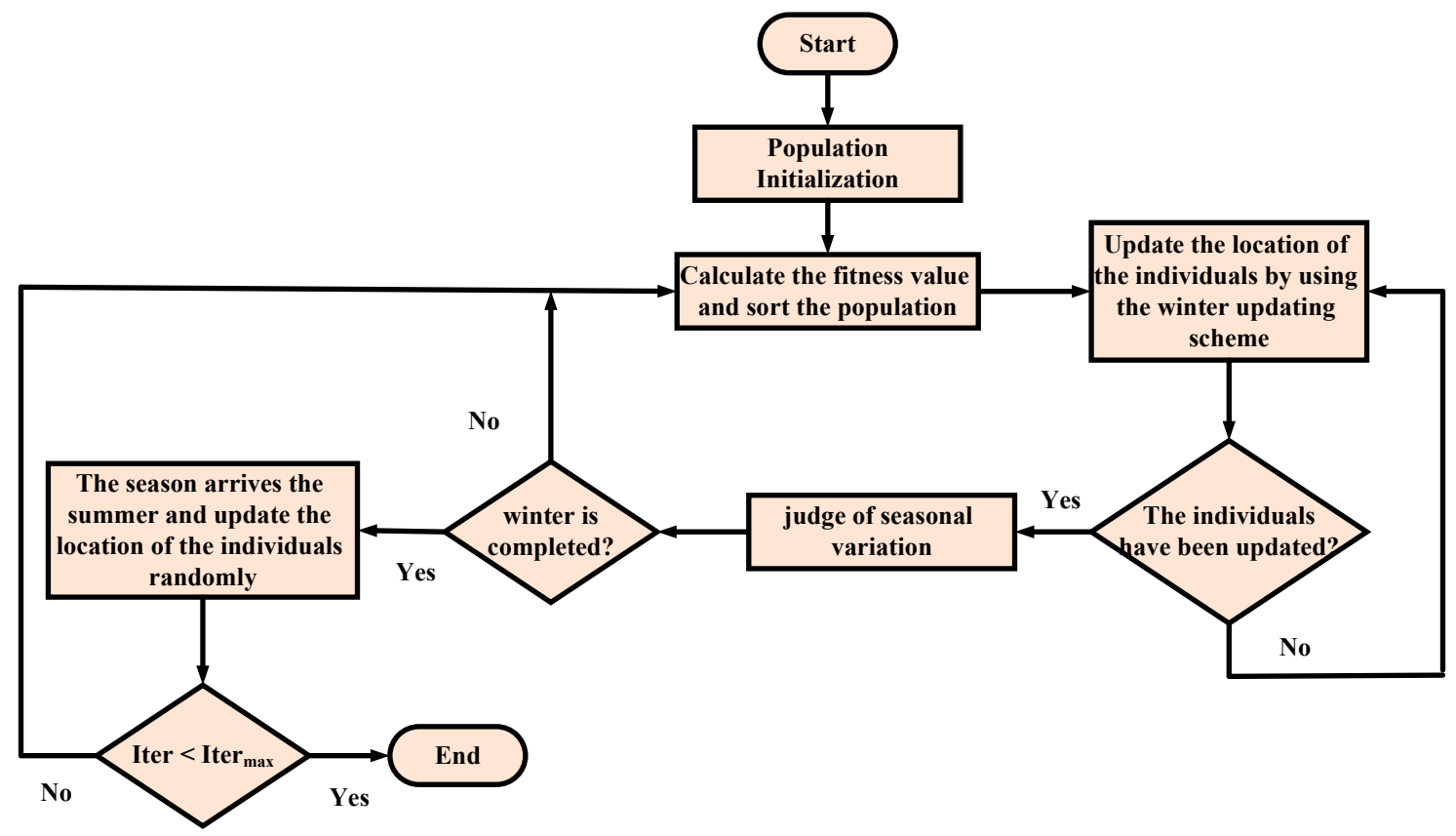

Figure 8. Flowchart of SSA.

Table 1. The values of optimal parameters of considered controllers using SSA.

\begin{tabular}{ccccccccccccc}
\hline Controller & $\alpha$ & $\beta$ & $\gamma$ & $K_{t}$ & $K_{i 1}$ & $K_{d 1}$ & $K_{p}$ & $K_{i 2}$ & $K_{d \mathbf{2}}$ & $\lambda$ & $\mu$ \\
\hline TID & - & - & - & -5.2 & -5.6 & -3.5 & - & - & - & - & - \\
FOPID & - & - & - & - & - & - & -10.1 & -10.8 & -5.2 & 0.76 & 0.2 \\
Proposed controller & 0.51 & 0.013 & 1.89 & 6.2 & 4.1 & 0.59 & -6.1 & 0.86 & 0.43 & 0.42 & 0.3 \\
\hline
\end{tabular}

\section{Simulation Results}

To investigate the efficiency of the proposed secondary controller and VIC, an islanded MG according to Figure 2 is considered. The simulation results and analyses were accomplished using MATLAB/Simulink software(R2019a, version 9.6.0.1072779). The simulation studies are divided into three subsections. In the first subsection, the frequency performance of the proposed 3DOF-TID\&FOPID cascade controller is evaluated and compared to TID and FOPID controllers under different load disturbances. The second subsection focuses on the dynamic performance of the proposed VIC-based BESS. To examine the efficiency of the proposed VIC-based BESS, the results have been compared with the conventional VIC-based BESS under different scenarios. Finally, the sensitivity analysis is carried out in the third subsection for the investigated MG by employing the proposed 3DOF-TID\&FOPID cascade controller under $\pm 25 \%$ changes in the parameters of $T_{g}$ and $T_{F C}$. Moreover, the sensitivity of the frequency deviation w.r.t. $L(s)$ is investigated in the third subsection.

\subsection{Impact of the 3DOF-TIDEFOPID Cascade Controller on MG Frequency Performance}

This subsection aims to evaluate the efficiency of the proposed controller as a secondary controller of the islanded MG. To evaluate the efficiency of the proposed controller, the simulation results are compared with TID and FOPID controllers under scenarios of step load deviation, a sequence of step load changes, and random load change. In this subsection, BESS is modeled by using conventional VIC.

\subsubsection{Step Load Change}

In this scenario, a $20 \%$ step load deviation in time $=0 \mathrm{~s}$ is applied to the islanded MG without the presence of the WTG and PV. Figure 9 shows the frequency responses of the 
studied MG using the TID, FOPID, and 3DOF-TID\&FOPID controllers. It is clear from Figure 9 that the frequency oscillations are eliminated faster using the proposed controller in comparison with TID and FOPID controllers. Moreover, Table 2 displays the dynamic characteristics of the considered controllers in terms of the maximum frequency deviation peak (MP), peak time (PT), and ITSE index. According to Table 2, it is obvious that the proposed controller has a lower MP, PT, and ITSE than other controllers. Hence, it can be said that the proposed controller provides better frequency performance than other controllers.

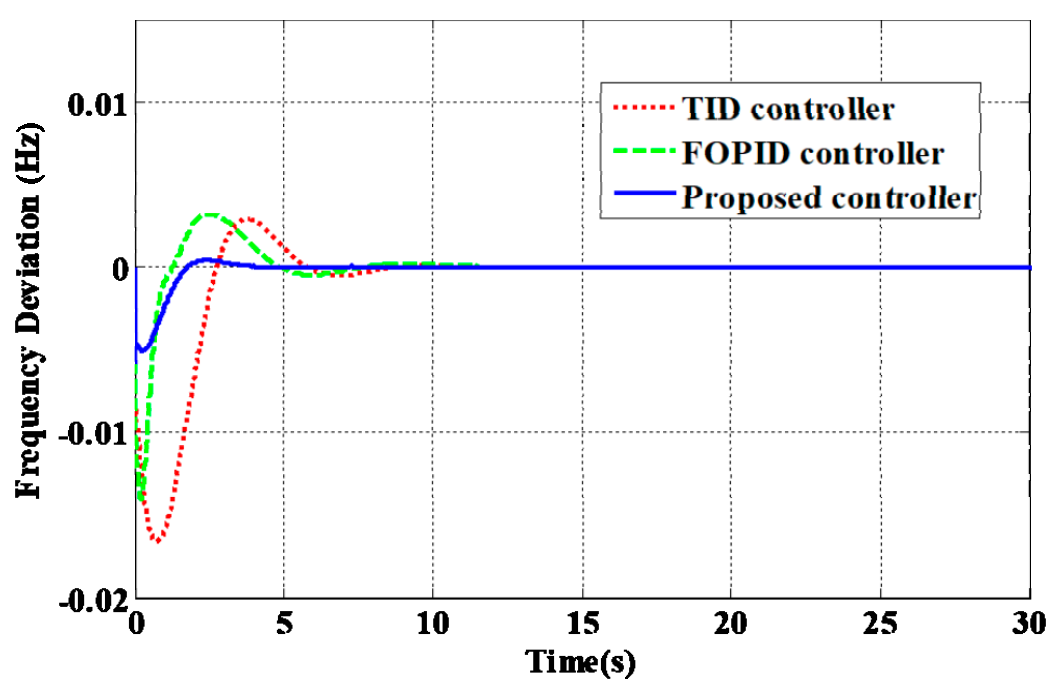

Figure 9. Resulted frequency responses for scenario 5.1.1.

Table 2. Dynamic characteristic of considered controllers for scenario 5.1.1.

\begin{tabular}{cccc}
\hline Controller Type & MP & PT & ITSE \\
\hline TID Controller & 0.01657 & 0.7682 & $2.0111 \times 10^{-4}$ \\
FOPID Controller & 0.01401 & 0.2146 & $9.7738 \times 10^{-5}$ \\
3DOF-TID\&FOPID Cascade Controller & 0.0057 & 0.0108 & $1.2475 \times 10^{-5}$ \\
\hline
\end{tabular}

\subsubsection{A Sequence of Step Load Changes}

In this scenario, a sequence of step load changes according to Figure 10a is applied to MG. Figure 10b,c show the output powers of the WTG and PV, respectively. The resulted frequency responses for this scenario are depicted in Figure 10d. With respect to Figure 10d, it can be obvious that the amplitude of the frequency fluctuations is significantly reduced by employing the proposed controller compared to other controllers. Therefore, like the previous scenario, it can be concluded that by employing the proposed controller as a secondary controller, the MG becomes stable faster than with the other controllers.

\subsubsection{Random Load Change}

To further investigate the effectiveness of the proposed control strategy, a disturbance according to Figure 11a is applied to MG. Additionally, Figure 11b,c exhibit the output power changes of WTG and PV, respectively. The results are indicated in Figure 11d. Obviously, the proposed controller provides lower fluctuation amplitude than the other controllers. 

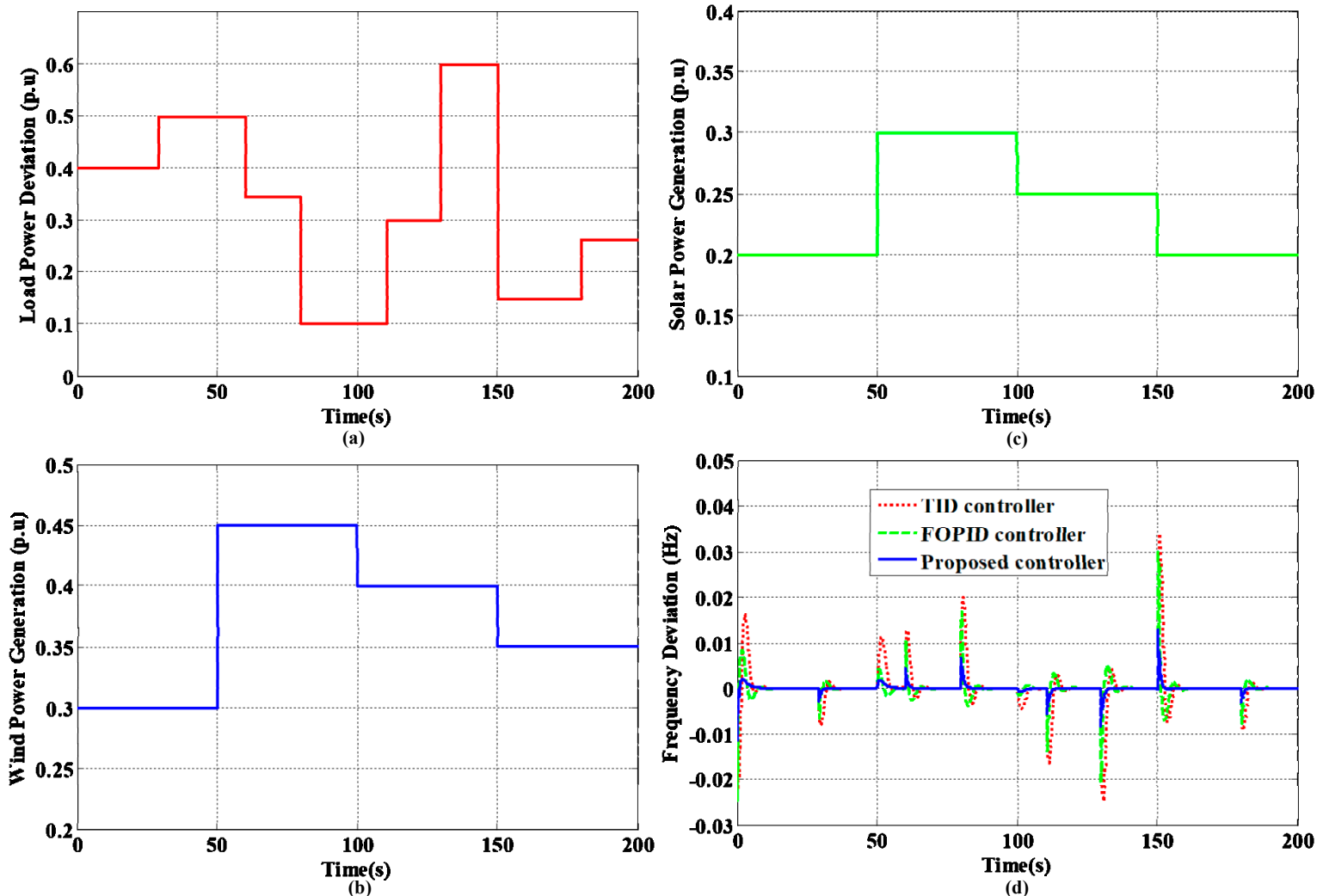

Figure 10. MG disturbances and frequency response for scenario 5.1.2. (a) Pattern of considered load disturbance. (b) WTG output power. (c) PV output power. (d) Resulted frequency responses.
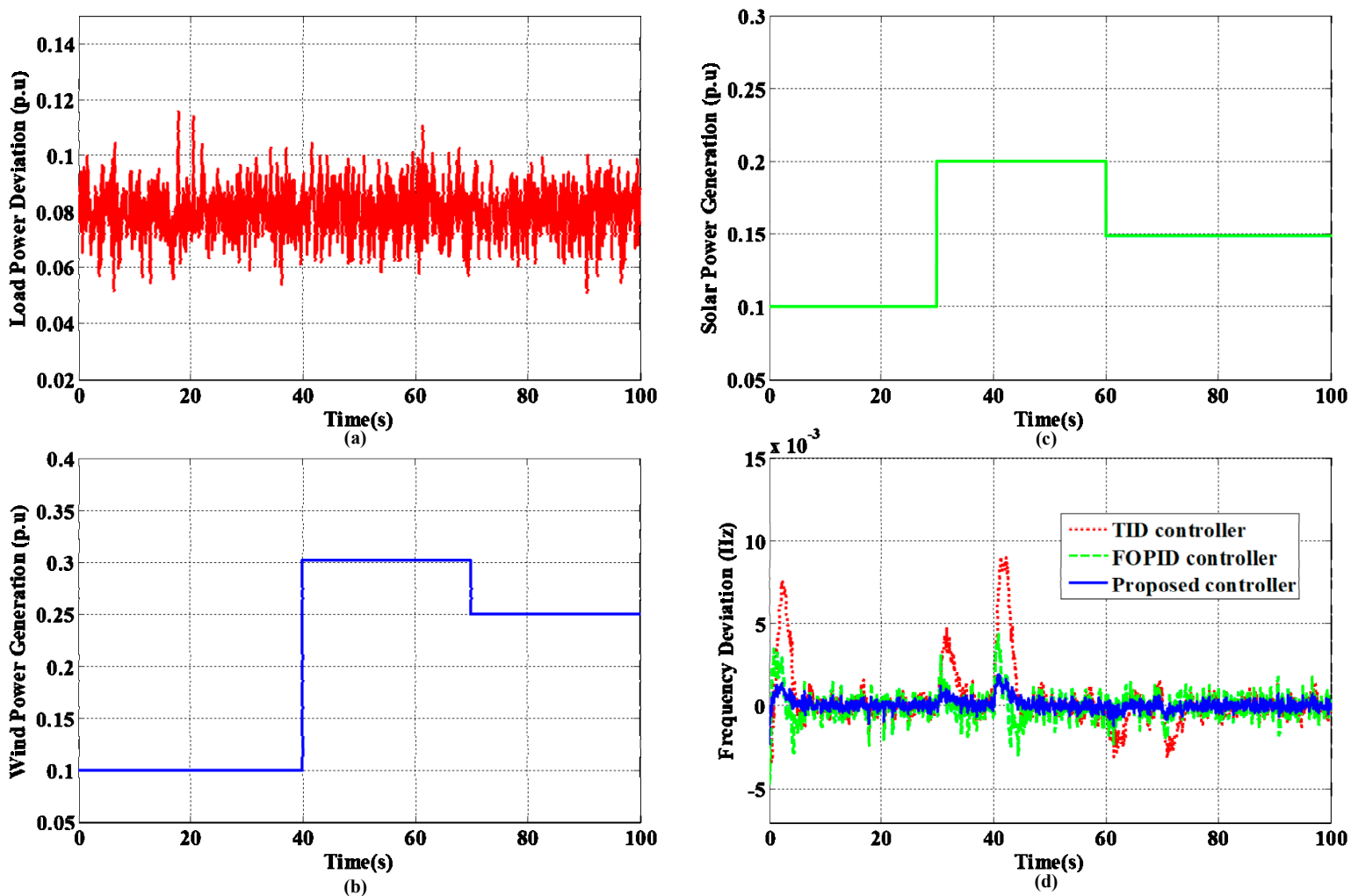

Figure 11. MG disturbances and frequency response for scenario 5.1.3. (a) Random load deviation pattern. (b) WTG output power. (c) PV output power. (d) Resulted frequency responses. 
From this subsection, it can be inferred that the proposed controller has better capability in capturing the load level uncertainties to generate the control command signals compared to the other controllers.

\subsection{Impact of the Proposed VIC on MG Frequency Performance}

In this subsection, the performance of the proposed VIC under the different operating situations and scenarios is investigated. The dynamic performance of the proposed VIC is compared to the conventional VIC under scenarios of a sequence of step load changes and random load change. In the scenario of the random load change, the performance of the proposed VIC is evaluated in three operating conditions: (1) normal operating condition, (2) $20 \%$ reduction in $K_{V I}$, and (3) $50 \%$ reduction in $K_{V I}$. It should be noted that the proposed 3DOF-TID\&FOPID cascade controller is considered as an MG secondary controller.

\subsubsection{A Sequence of Step Load Changes}

According to Figure 12a, a sequence of step load changes is applied to MG. The variations of the output powers of WTG and PV for this scenario are depicted in Figure 12b,c, respectively. Figure $12 \mathrm{~d}$ indicates the MG frequency responses by employing conventional and proposed VICs. From Figure 12d, it is evident that the proposed VIC provides better efficiency in damping of the swings and reducing the amplitude of the swings compared to the conventional VIC.


Figure 12. MG disturbances and frequency response for scenario 5.2.1. (a) Considered load disturbance pattern. (b) WTG output power. (c) PV output power. (d) Resulted frequency responses.

\subsubsection{Random Load Change}

In this scenario, the effectiveness of the proposed VIC-based BESS is evaluated by considering the severe disturbance and high penetration of the WTG and PV under three operating conditions: (1) normal operating condition, (2) $20 \%$ reduction in $K_{V I}$, and (3) $50 \%$ reduction in $K_{V I}$. A severe disturbance for a time interval of $700 \mathrm{~s}$ according to Figure 13a is considered. The output powers of the WTG and PV for this scenario are shown in Figure $13 b, c$, respectively. 

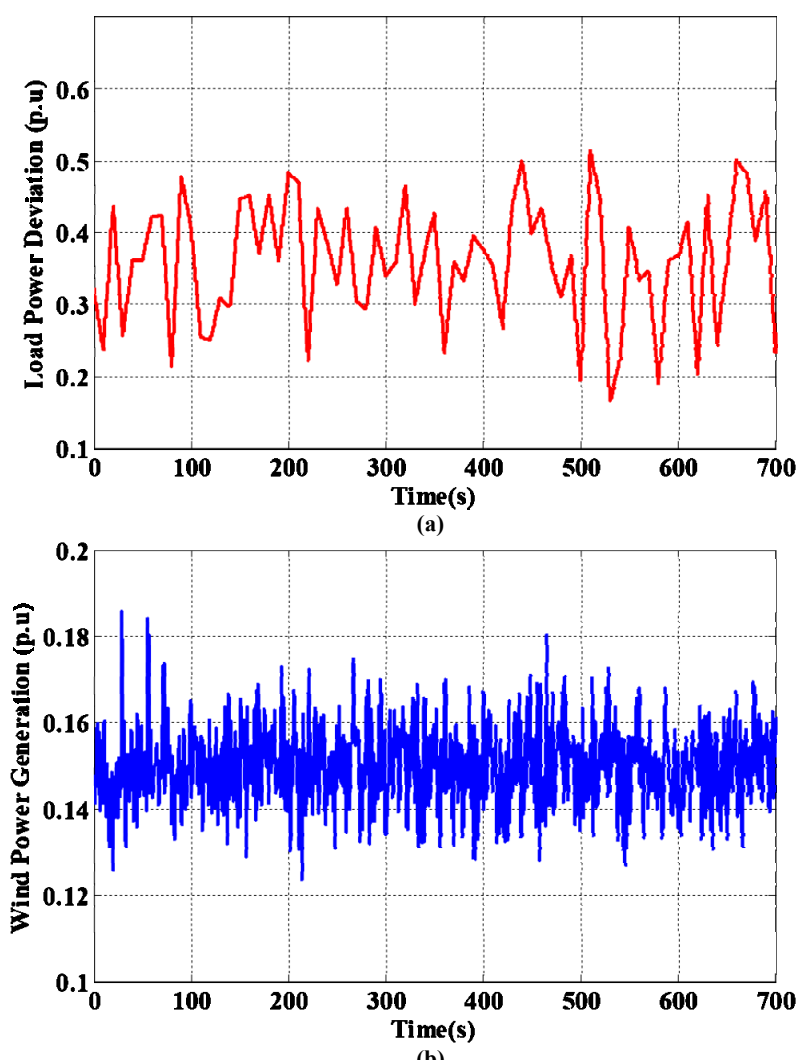

(b)

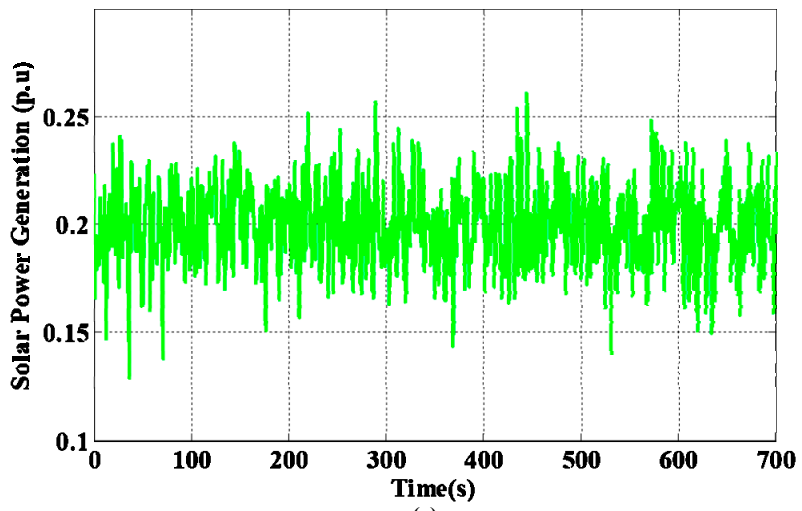

(c)

Figure 13. MG disturbances for Section 5.2.2. (a) Random load deviation. (b) WTG output power. (c) PV output power.

\subsubsection{Nominal Operating Condition}

First, the proposed VIC performance is investigated under normal conditions (the nominal $K_{V I}$ value). The MG frequency responses by employing the conventional and proposed VICs under the normal condition are shown in Figure 14a. As illustrated in Figure 14a, the amplitude of the frequency deviations by using the proposed VIC is significantly reduced in comparison with conventional VIC. According to Figure 14a, due to the connection of PV and WTG to MG at times $=100$ and $200 \mathrm{~s}$ respectively, it causes the frequency rise of +0.0084 and $+0.006 \mathrm{~Hz}$ for the case of the conventional VIC, and +0.0047 and $+0.0033 \mathrm{~Hz}$ for the case of the proposed VIC. Additionally, due to the connection of load disturbance at time $=0 \mathrm{~s}$, disconnection of PV and WTG at times $=500$ and $600 \mathrm{~s}$ respectively, it results in the frequency drop of $-0.0139,-0.0086$, and $-0.0061 \mathrm{~Hz}$ for the case of the conventional VIC, and $-0.0078,-0.0046$, and $-0.0035 \mathrm{~Hz}$ for the case of the proposed VIC. Figure 14b,c demonstrate the output powers of the conventional VIC-based BESS and proposed VIC-based BESS for normal conditions, respectively. The positive and 
negative values show charging and discharging powers. It was found that BESS equipped by the proposed VIC is charged/discharged more than BESS equipped by the conventional VIC in response to applied perturbations. Hence, it can be said that the proposed VIC is superior to the conventional VIC in improving the MG frequency stability.

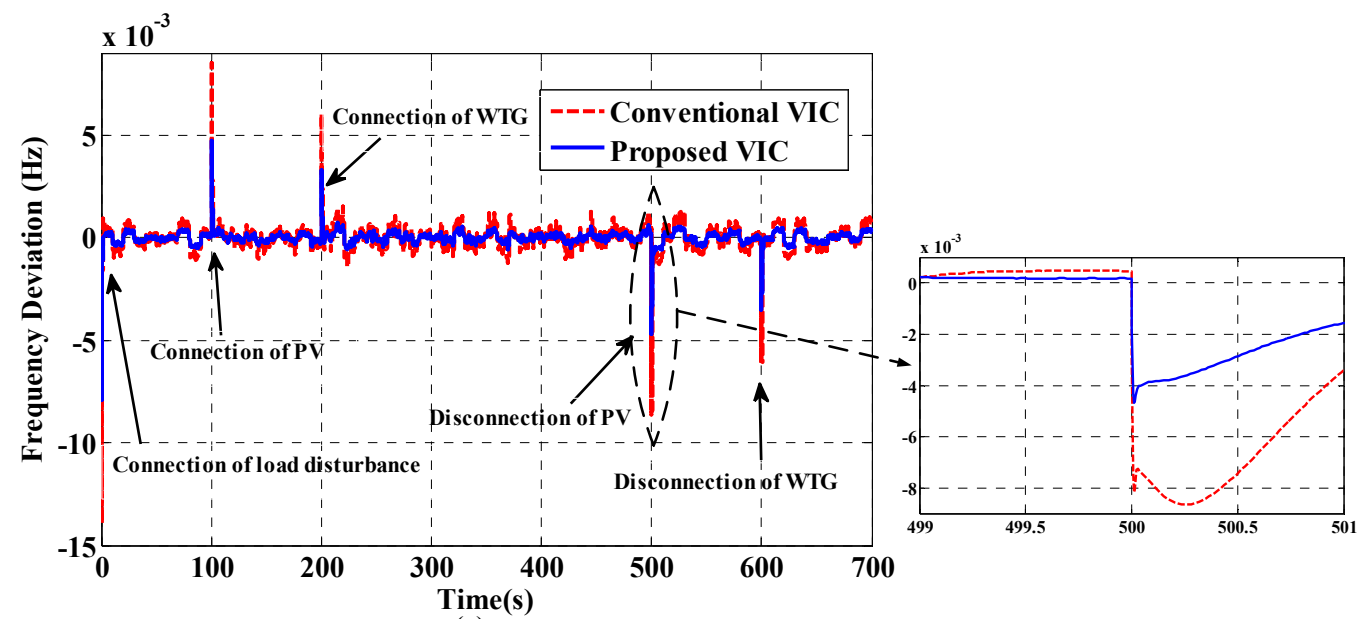

(a)
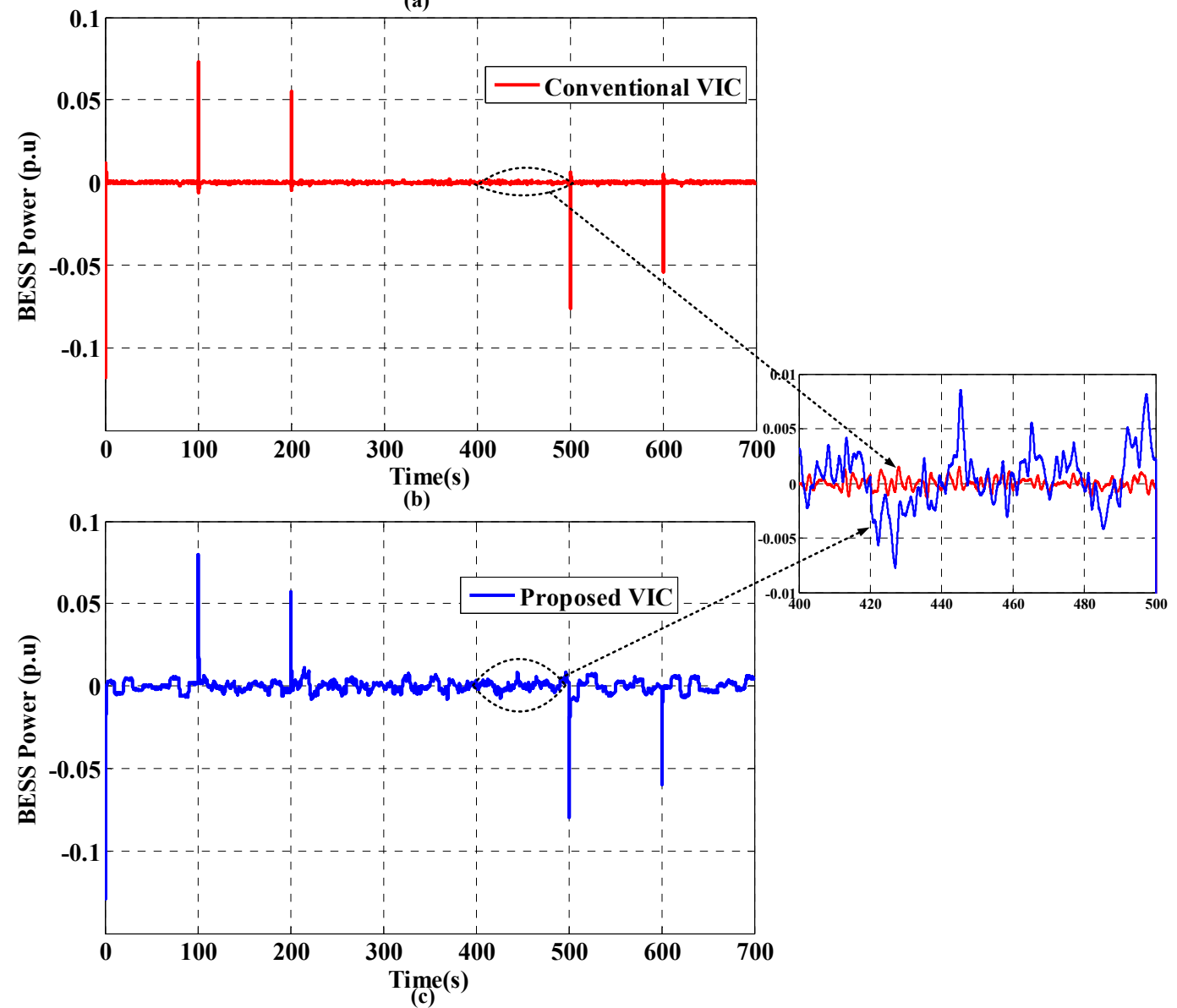

Figure 14. MG dynamic responses for scenario in Section 5.2.2.1. (a) Resulted frequency responses. (b) Power of conventional VIC-based BESS. (c) Power of proposed VIC-based BESS.

Now, the proposed VIC performance is studied under critical conditions, i.e., $20 \%$ reduction in $K_{V I}$ value $\left(K_{V I}=0.8\right)$ and $50 \%$ reduction in $K_{V I}$ value $\left(K_{V I}=0.5\right)$. 


\subsubsection{2. $20 \%$ Reduction in $\mathrm{K}_{\mathrm{VI}}$}

Figure 15a illustrates the MG frequency responses under the situation of the $20 \%$ reduction in $K_{V I}$ value. With respect to this condition, the results show that the BESS based on the proposed VIC is more effective in handling the applied disturbances to MG and damping the frequency deviations in comparison with the BESS based on the conventional VIC. The maximum frequency deviation in the case of the conventional VIC has driven to $-0.015 \mathrm{~Hz}$, while for the proposed VIC, the maximum frequency amplitude is $-0.0085 \mathrm{~Hz}$. The BESS power changes equipped by conventional and proposed VICs are depicted in Figure 15b,c, respectively. From Figure 15b,c, it is obvious that BESS based on the proposed VIC provides faster and better performance in charging/discharging power than the conventional VIC-based BESS.
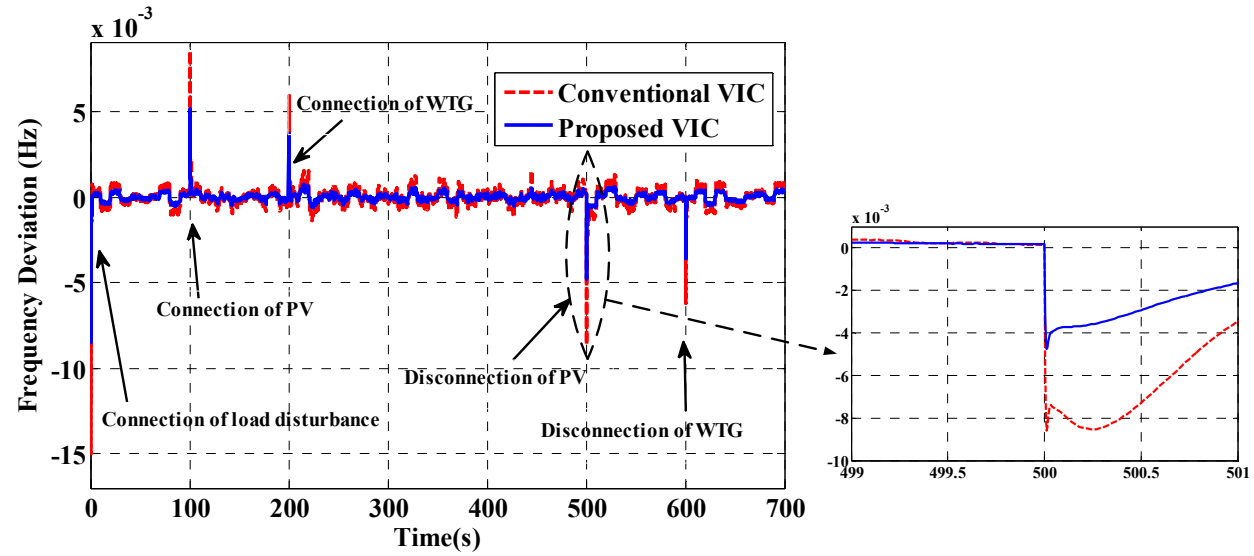

(a)

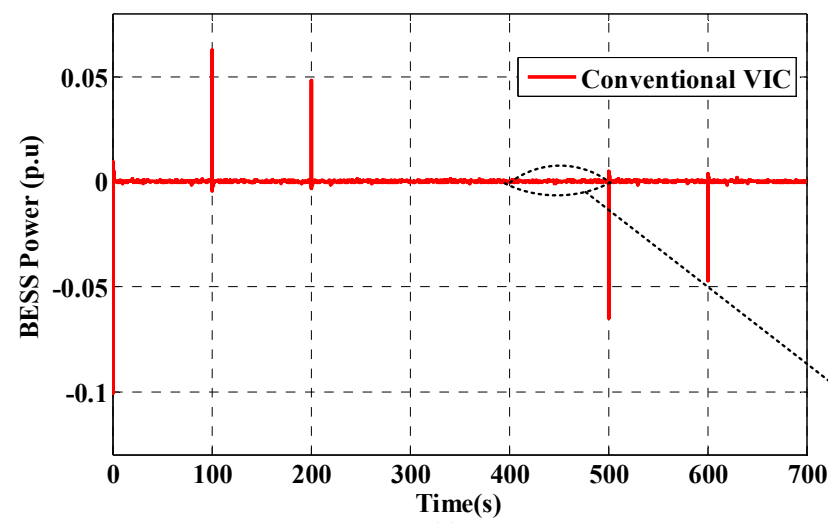

(b)
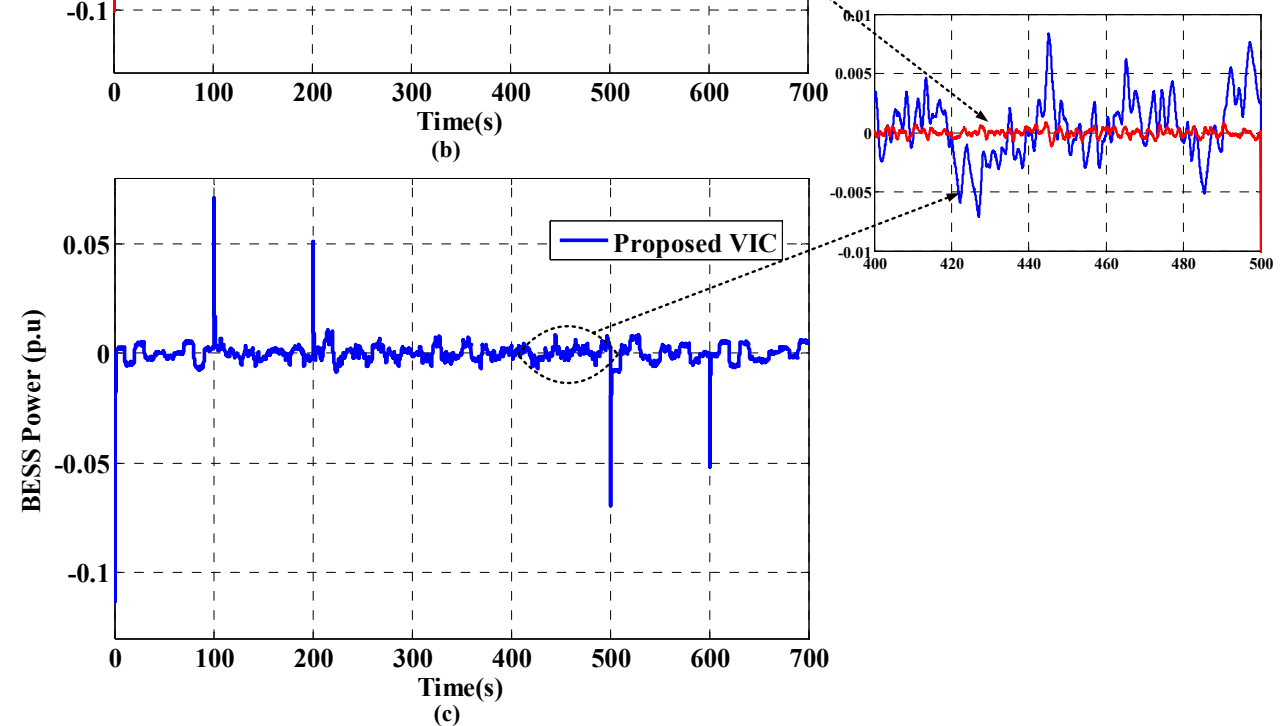

Figure 15. MG dynamic responses for scenario in Section 5.2.2.2. (a) Resulted frequency responses. (b) Power of conventional VIC-based BESS. (c) Power of proposed VIC-based BESS. 


\subsubsection{3. $50 \%$ Reduction in $\mathrm{K}_{\mathrm{VI}}$}

To create the scenario more critically, the MG is operated under the situation of a $50 \%$ reduction in $K_{V I}$ value and considering high penetration of PV and WTG. Figure 16a indicates the MG frequency responses under this situation. From Figure 16a, it can be concluded that a much better frequency response is obtained from the proposed VICbased BESS. The BESS power changes based on the conventional and proposed VICs are demonstrated in Figure 16b,c, respectively. The comparison of Figure 16b,c clearly illustrates that the proposed VIC-based BESS is efficiently charged/discharged compared to the conventional VIC-based BESS in response to severe perturbations and contingencies.
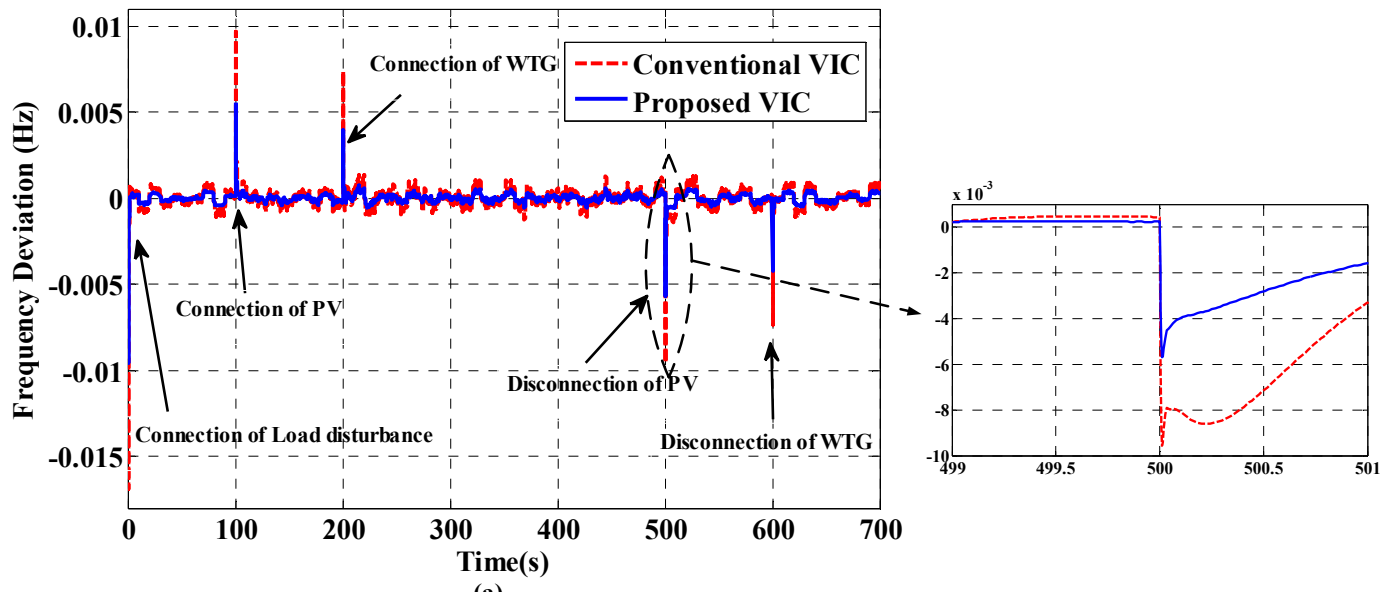

(a)

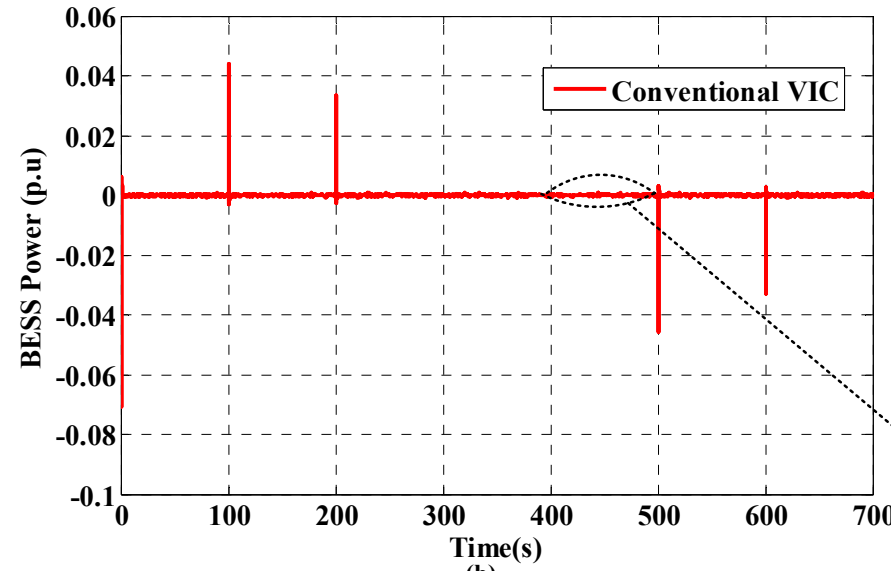

(b)
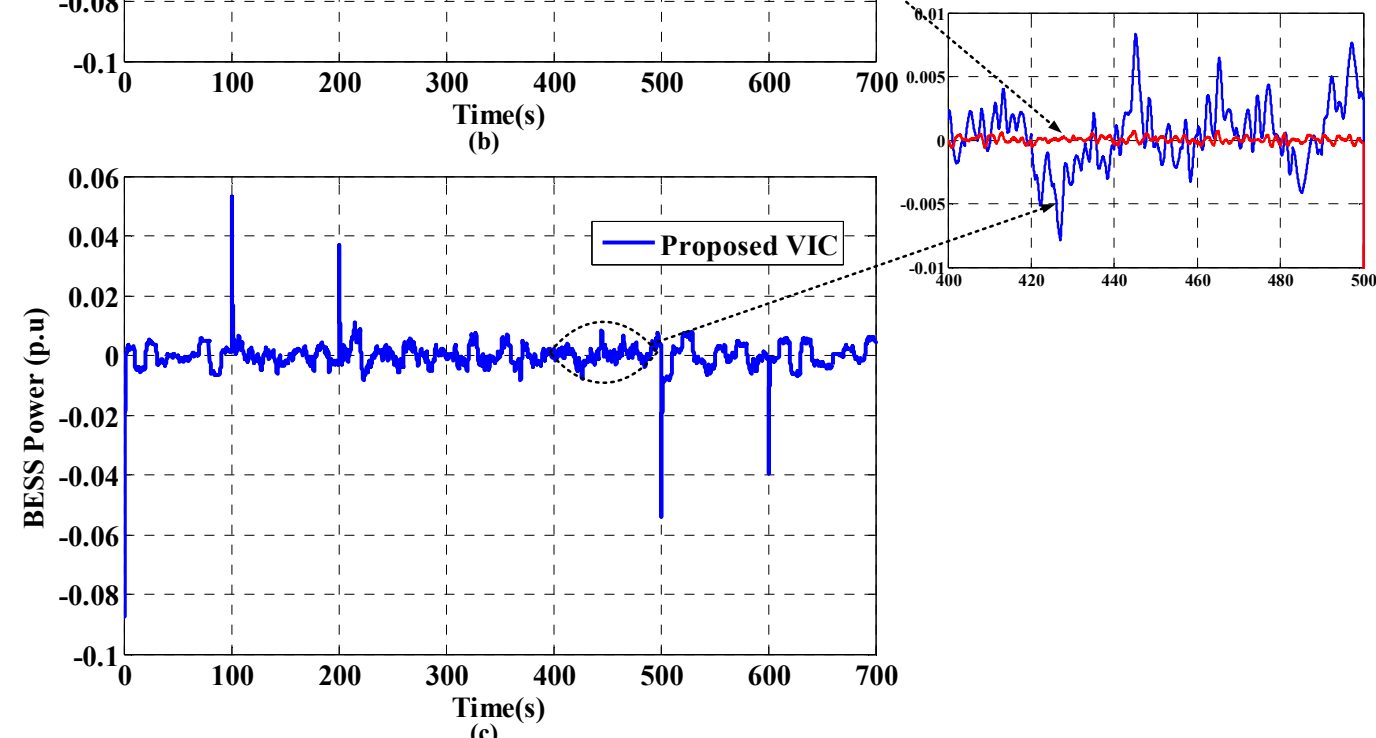

(c)

Figure 16. MG dynamic responses for scenario in Section 5.2.2.3. (a) Resulted frequency responses. (b) Power of conventional VIC-based BESS. (c) Power of proposed VIC-based BESS. 


\subsection{Impact of the Changes of the Parameters on the Proposed 3DOF-TIDEFOPID Cascade Controller Performance}

This subsection investigates the robustness of the 3DOF-TID\&FOPID cascade controller versus the variations of the parameters. Therefore, $\pm 25 \%$ changes are applied to the parameters of $T_{g}$ and $T_{F C}$. The sensitivity analysis is accomplished under a $10 \%$ step load perturbation without the presence of PV and WTG. BESS is modeled by using the proposed VIC. Moreover, the adjustable parameters of the proposed 3DOF-TID\&FOPID cascade controller are optimized only for the nominal condition. Figure $17 \mathrm{a}, \mathrm{b}$ demonstrate the frequency responses of the proposed 3DOF-TID\&FOPID cascade controller for $\pm 25 \%$ changes in parameters of $T_{g}$ and $T_{F C}$, respectively. As seen, the MG frequency responses under the considered changes are almost identical. The dynamic characteristics for the considered changes are shown in Table 3. According to Table 3, it is obvious that the dynamic characteristics of the MG frequency responses are not affected remarkably after considering such changes. Hence, MG still remains stable.
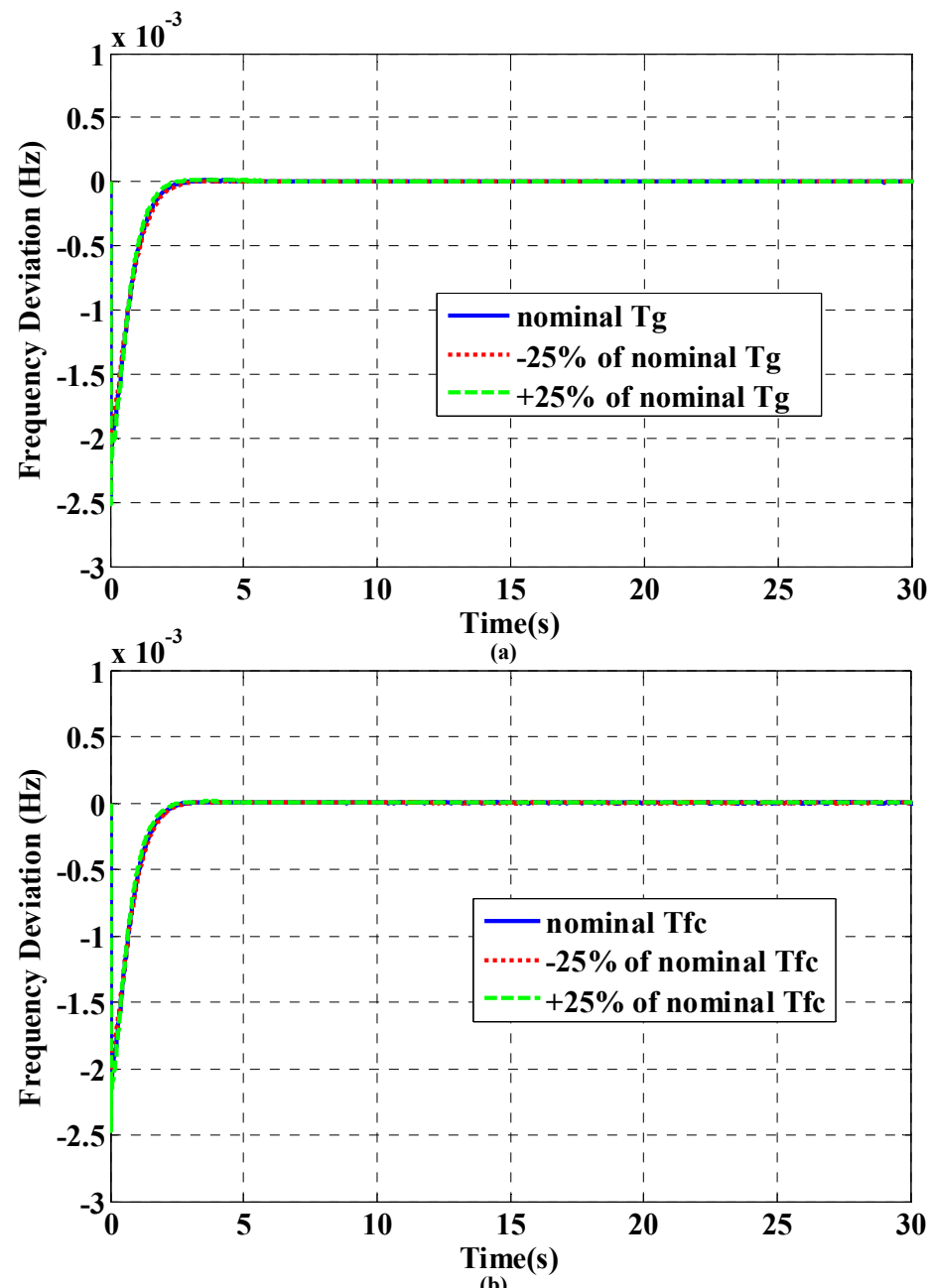

Figure 17. Sensitivity analysis of the MG by employing the proposed controller during $\pm 25 \%$ variations in (a) $T_{g}$ and (b) $T_{F C}$. 
Table 3. Sensitivity analysis for the proposed controller under $\pm 25 \%$ variations in $\mathrm{T}_{\mathrm{DEG}}$ and $\mathrm{T}_{\mathrm{FC}}$.

\begin{tabular}{|c|c|c|c|c|c|}
\hline Controller & & Signal & MP & PT & ITSE \\
\hline & $+25 \%$ & $\Delta F$ & 0.002519 & 0.01136 & $1.4856 \times 10^{-6}$ \\
\hline & $-25 \%$ & $\Delta F$ & 0.002353 & 0.01101 & $1.5130 \times 10^{-6}$ \\
\hline \multicolumn{6}{|c|}{ 3DOF-TID\&FOPID Cascade Controller } \\
\hline & $+25 \%$ & $\Delta F$ & 0.002469 & 0.01122 & $1.4569 \times 10^{-6}$ \\
\hline & \multicolumn{5}{|c|}{$\mathrm{T}_{\mathrm{FC}}$} \\
\hline & $-25 \%$ & $\Delta F$ & 0.002429 & 0.01122 & $1.5305 \times 10^{-6}$ \\
\hline
\end{tabular}

Now, the sensitivity of frequency response deviation w.r.t. $L(s)$ is investigated. Based on Figure 2, the frequency deviation of MG w.r.t. $\Delta P_{L}(s)$ is written as:

$$
T(s)=\frac{\Delta f(s)}{\Delta P_{L}(s)}=\underbrace{\frac{-L(s)}{1-L(s)[C(s)-N(s)-B(s)+K(s)-F(s)]}}_{W(s)}
$$

where

$$
\begin{aligned}
& L(s)=(M s+D)^{-1}, C(s)=\left(D_{V I}+s K_{V I}+\frac{1}{R_{B E S S}}\right) \\
& N(s)=\left(1+s T_{B E S S}\right)^{-1}, B(s)=\left(1+s T_{t}\right)^{-1}\left(1+s T_{g}\right)^{-1} P(s) \\
& K(s)=\left(1+s T_{t}\right)^{-1}\left(1+s T_{g}\right)^{-1} \frac{1}{R} \\
& F(s)=\left(1+s T_{t}\right)^{-1}\left(1+s T_{g}\right)^{-1}\left(1+s T_{F C}\right)^{-1} P(s)
\end{aligned}
$$

$P(s)$ shows the output of the secondary controller. The derivative of $T(s)$ w.r.t. $L(s)$ is written as:

$$
\frac{\partial T(s)}{\partial L(s)}=\frac{-1}{W^{2}(s)}
$$

Then, the sensitivity of the $\Delta f$ w.r.t. $L(s)$ can be calculated as:

$$
S(s)=\frac{\partial T(s)}{\partial L(s)} / \frac{T(s)}{L(s)}=\frac{-1}{W^{2}(s)} / \frac{-1}{W(s)}=\frac{1}{W(s)}
$$

Figure 18 shows the sensitivity of the $\Delta f$ w.r.t. $L(s)$. As can be seen, the system has a slight sensitivity to the $L(s)$ in the presence of the proposed controller.

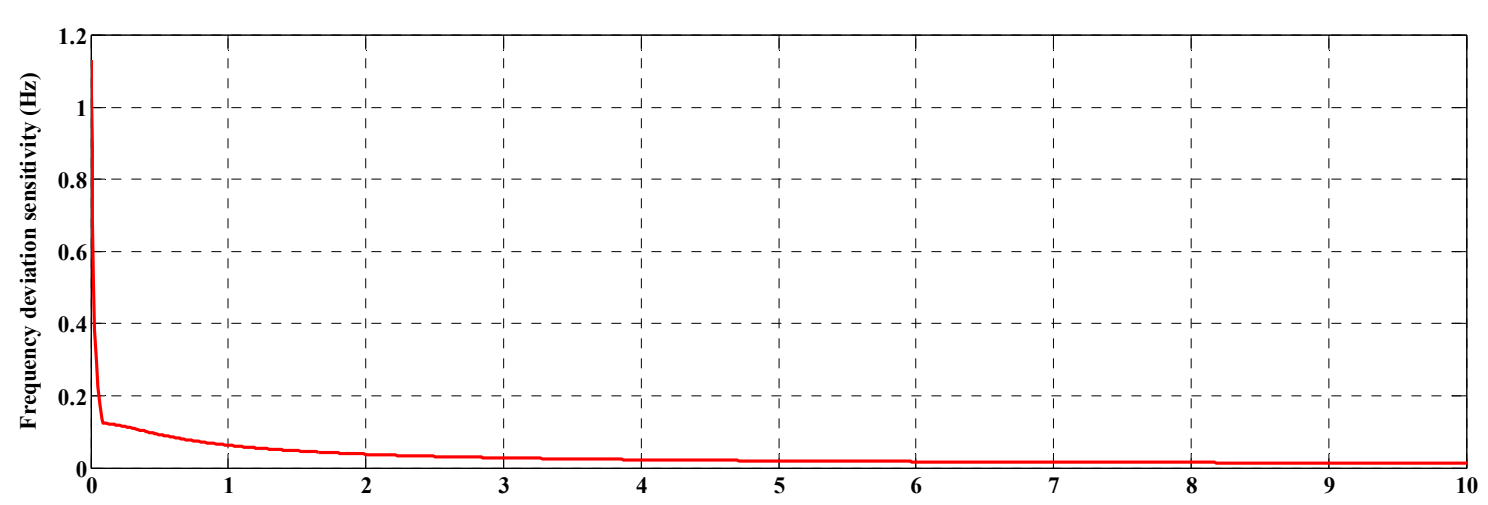

Figure 18. Frequency deviation sensitivity w.r.t. $L(s)$ by employing the proposed controller.

\section{Conclusions}

This paper investigated the frequency regulation problem of the islanded MGs considering high penetration of the RESs. In such MGs, when an imbalance between generation 
power and demand occurs, the system damping, inertia response, and primary frequency control are lowered, and MG frequency stability is threatened. To meet these challenges, this paper presented a novel modeling for VIC and a cascade controller based on a combination of the FOCs and 3DOF as a secondary controller. The proposed modeling for VIC simulates the primary frequency control, virtual inertia, and damping, simultaneously. To evaluate the dynamic efficiency of the proposed VIC modeling, its performance was compared with the conventional VIC under different disturbances and operating conditions. The results clearly showed that the proposed VIC significantly improved the MG frequency performance in comparison with the conventional VIC. In order to investigate the effectiveness of the proposed controller, the dynamic performance of this controller was compared with the TID and FOPID controllers. Additionally, the SSA was utilized to optimize the adjustable coefficients of the considered controllers. The simulation results indicated that the proposed controller provided much better frequency responses in comparison with the TID and FOPID controllers. Eventually, the sensitivity analysis was performed to study the efficiency of the proposed controller in the face of uncertainties of MG coefficients. The results illustrated that the proposed controller is robust versus the uncertainties of the coefficients.

Author Contributions: S.O. (Soroush Oshnoei): Writing-original draft, software, and methodology; M.A.: Investigation and validation; S.O. (Siavash Oshnoei): Formal analysis, resources, writingreview and editing; A.O.: Conceptualization, data curation, writing-review and editing; B.M.-I.: Supervision, writing-review and editing. All authors have read and agreed to the published version of the manuscript.

Funding: Behnam Mohammadi-Ivatloo would like to thank the supports provided by QNRF-Qatar National Research Fund under grant number of SARA-HBKU-SRO-NPRP12S-0125-190013\#UoT.

Institutional Review Board Statement: Not applicable.

Informed Consent Statement: Not applicable.

Data Availability Statement: Data sharing not applicable.

Conflicts of Interest: The authors declare no conflict of interest.

\section{Appendix A}

$f=60 \mathrm{~Hz}, M=0.1167, D=0.015, K_{P V}=1, T_{P V}=1.8 \mathrm{~s}, K_{W T G}=1, T_{W T G}=1.5 \mathrm{~s}$, $T_{I N}=0.04 \mathrm{~s}, T_{I C}=0.004 \mathrm{~s}, T_{F C}=0.28 \mathrm{~s}, T_{g}=0.4 \mathrm{~s}, T_{t}=0.01 \mathrm{~s}, R=2.4 \mathrm{pu} \mathrm{Hz} / \mathrm{MW}$, $T_{F E S S}=0.1 \mathrm{~s}, T_{B E S S}=0.1 \mathrm{~s}, K_{V I}=1$.

\section{References}

1. Aghdam, F.H.; Kalantari, N.; Mohammadi-Ivatloo, B. A stochastic optimal scheduling of multi-microgrid systems considering emissions: A chance constrained model. J. Clean. Prod. 2020, 275, 122965. [CrossRef]

2. Daneshvar, M.; Mohammadi-Ivatloo, B.; Zare, K.; Asadi, S.; Anvari-Moghaddam, A. A novel operational model for interconnected microgrids participation in transactive energy market: A hybrid IGDT/stochastic approach. IEEE Trans. Ind. Inform. 2020, 17, 4025-4035. [CrossRef]

3. Calise, F.; Duic, N.; Pfeifer, A.; Vicidomini, M.; Orlando, A. Moving the system boundaries in decarbonization of large islands. Energy Convers. Manag. 2021, 234, 113956. [CrossRef]

4. Nastasi, B.; Mazzoni, S.; Groppi, D.; Romagnoli, A.; Garcia, D.A. Solar power-to-gas application to an island energy system. Renew. Energy 2021, 164, 1005-1016. [CrossRef]

5. Mekonnen, T.; Bhandari, R.; Ramayya, V. Modeling, Analysis and Optimization of Grid-Integrated and Islanded Solar PV Systems for the Ethiopian Residential Sector: Considering an Emerging Utility Tariff Plan for 2021 and Beyond. Energies 2021, 14, 3360. [CrossRef]

6. Pazmiño, I.; Martinez, S.; Ochoa, D. Analysis of Control Strategies Based on Virtual Inertia for the Improvement of Fre-quency Stability in an Islanded Grid with Wind Generators and Battery Energy Storage Systems. Energies 2021, 14, 698. [CrossRef]

7. Xing, J.; Wu, P. Optimal Planning of Electricity-Natural Gas Coupling System Considering Power to Gas Facilities. Energies 2021, 14, 3400. [CrossRef]

8. Bevrani, H.; Feizi, M.R.; Ataee, S. Robust Frequency Control in an Islanded Microgrid: $H_{\infty}$ and $\mu$-Synthesis Approaches. IEEE Trans. Smart Grid 2015, 7, 706-717. [CrossRef] 
9. Oshnoei, S.; Aghamohammadi, M.; Oshnoei, S. A Novel Fractional order controller based on Fuzzy Logic for Regulating the Frequency of an Islanded Microgrid. In Proceedings of the 2019 International Power System Conference (PSC), Tehran, Iran, 9-11 December 2019; pp. 320-326. Available online: https:/ / ieeexplore.ieee.org/abstract/document/9081567 (accessed on 9 July 2021).

10. Kayalvizhi, S.; Kumar, D.V. Load frequency control of an isolated micro grid using fuzzy adaptive model predictive control. IEEE Access 2017, 5, 16241-16251. [CrossRef]

11. Fathi, A.; Shafiee, Q.; Bevrani, H. Robust Frequency Control of Microgrids Using an Extended Virtual Synchronous Generator. IEEE Trans. Power Syst. 2018, 33, 6289-6297. [CrossRef]

12. Kerdphol, T.; Rahman, F.S.; Mitani, Y.; Watanabe, M.; Küfeoğlu, S. Robust Virtual Inertia Control of an Islanded Microgrid Considering High Penetration of Renewable Energy. IEEE Access 2018, 6, 625-636. [CrossRef]

13. Fini, M.H.; Golshan, M.E.H. Determining optimal virtual inertia and frequency control parameters to preserve the frequency stability in islanded microgrids with high penetration of renewables. Electr. Power Syst. Res. 2018, 154, 13-22. [CrossRef]

14. Kerdphol, T.; Rahman, F.S.; Watanabe, M.; Mitani, Y. Robust virtual inertia control of a low inertia microgrid considering frequency measurement effects. IEEE Access 2019, 7, 57550-57560. [CrossRef]

15. Mosca, C.; Arrigo, F.; Mazza, A.; Bompard, E.; Carpaneto, E.; Chicco, G.; Cuccia, P. Mitigation of frequency stability issues in low inertia power systems using synchronous compensators and battery energy storage systems. IET Gener. Transm. Distrib. 2019, 13, 3951-3959. [CrossRef]

16. Chamorro, H.R.; Riaño, I.; Gerndt, R.; Zelinka, I.; Gonzalez-Longatt, F.; Sood, V.K. Synthetic inertia control based on fuzzy adaptive differential evolution. Int. J. Electr. Power Energy Syst. 2019, 105, 803-813. [CrossRef]

17. Ali, H.; Magdy, G.; Li, B.; Shabib, G.; Elbaset, A.A.; Xu, D.; Mitani, Y. A New Frequency Control Strategy in an Islanded Microgrid Using Virtual Inertia Control-Based Coefficient Diagram Method. IEEE Access 2019, 7, 16979-16990. [CrossRef]

18. Zhang, X.; Zhu, Z.; Fu, Y.; Shen, W. Multi-objective virtual inertia control of renewable power generator for transient stability improvement in interconnected power system. Int. J. Electr. Power Energy Syst. 2020, 117, 105641. [CrossRef]

19. Kerdphol, T.; Rahman, F.S.; Watanabe, M.; Mitani, Y.; Turschner, D.; Beck, H.-P. Enhanced Virtual Inertia Control Based on Derivative Technique to Emulate Simultaneous Inertia and Damping Properties for Microgrid Frequency Regulation. IEEE Access 2019, 7, 14422-14433. [CrossRef]

20. Dreidy, M.; Mokhlis, H.; Mekhilef, S. Inertia response and frequency control techniques for renewable energy sources: A re-view. Renew. Sustain. Energy Rev. 2017, 69, 144-155. [CrossRef]

21. Khezri, R.; Oshnoei, A.; Oshnoei, S.; Bevrani, H.; Muyeen, S. An intelligent coordinator design for GCSC and AGC in a two-area hybrid power system. Appl. Soft Comput. 2019, 76, 491-504. [CrossRef]

22. Oshnoei, A.; Khezri, R.; Ghaderzadeh, M.; Parang, H.; Oshnoei, S.; Kheradmandi, M. Application of IPSO algorithm in DFIGbased wind turbines for efficient frequency control of multi-area power systems. In Proceedings of the 2017 Smart Grid Conference (SGC), Tehran, Iran, 20-21 December 2017; pp. 1-6.

23. Oshnoei, A.; Kheradmandi, M.; Muyeen, S.M. Robust Control Scheme for Distributed Battery Energy Storage Systems in Load Frequency Control. IEEE Trans. Power Syst. 2020, 35, 4781-4791. [CrossRef]

24. Oshnoei, A.; Kheradmandi, M.; Muyeen, S.M.; Hatziargyriou, N.D. Disturbance Observer and Tube-based Model Predictive Controlled Electric Vehicles for Frequency Regulation of an Isolated Power Grid. IEEE Trans. Smart Grid 2021, 1. [CrossRef]

25. Oshnoei, A.; Kheradmandi, M.; Oshnoei, S. Optimal model predictive control of photovoltaic plants for frequency regulation in an interconnected power system. In Proceedings of the 2019 International Power System Conference (PSC), Tehran, Iran, 9-11 December 2019; pp. 428-433.

26. Oshnoei, A.; Khezri, R.; Muyeen, S.M.; Oshnoei, S.; Blaabjerg, F. Automatic generation control incorporating electric vehicles. Electr. Power Compon. Syst. 2019, 47, 720-732. [CrossRef]

27. Oshnoei, S.; Oshnoei, A.; Mosallanejad, A.; Haghjoo, F. Novel load frequency control scheme for an interconnected two-area power system including wind turbine generation and redox flow battery. Int. J. Electr. Power Energy Syst. 2021, 130, 107033. [CrossRef]

28. Rahman, A.; Saikia, L.C.; Sinha, N. Automatic generation control of an unequal four-area thermal system using biogeographybased optimised 3DOF-PID controller. IET Gener. Transm. Distrib. 2016, 10, 4118-4129. [CrossRef]

29. Prakash, A.; Murali, S.; Shankar, R.; Bhushan, R. HVDC tielink modeling for restructured AGC using a novel fractional order cascade controller. Electr. Power Syst. Res. 2019, 170, 244-258. [CrossRef]

30. Kumari, S.; Shankar, G. Maiden application of cascade tilt-integral-tilt-derivative controller for performance analysis of load frequency control of interconnected multi-source power system. IET Gener. Transm. Distrib. 2019, 13, 5326-5338. [CrossRef]

31. Arya, Y. Improvement in automatic generation control of two-area electric power systems via a new fuzzy aided optimal PIDN-FOI controller. ISA Trans. 2018, 80, 475-490. [CrossRef]

32. Tasnin, W.; Saikia, L.C. Deregulated AGC of multi-area system incorporating dish-Stirling solar thermal and geothermal power plants using fractional order cascade controller. Int. J. Electr. Power Energy Syst. 2018, 101, 60-74. [CrossRef]

33. Oshnoei, S.; Oshnoei, A.; Mosallanejad, A.; Haghjoo, F. Contribution of GCSC to regulate the frequency in multi-area power systems considering time delays: A new control outline based on fractional order controllers. Int. J. Electr. Power Energy Syst. 2020, 123, 106197. [CrossRef] 
34. Jain, M.; Singh, V.; Rani, A. A novel nature-inspired algorithm for optimization: Squirrel search algorithm. Swarm Evol. Comput. 2019, 44, 148-175. [CrossRef]

35. Basu, M. Squirrel search algorithm for multi-region combined heat and power economic dispatch incorporating renewable energy sources. Energy 2019, 182, 296-305. [CrossRef] 